\title{
Tratamento de dados climáticos de Santa Maria, RS, para análise de desempenho térmico de edificações
}

\author{
Climate data processing for the thermal performance \\ analysis of buildings in Santa Maria, $R S$
}

\section{Giane de Campos Grigoletti Michelle Gomes Flores Joaquim Cesar Pizzutti dos Santos}

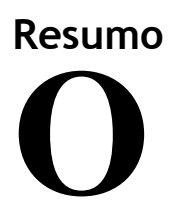

tratamento e a disponibilização de dados climáticos para projeto de edificações são importantes para seu desempenho térmico e eficiência energética. O Ano Climático de Referência (TRY), o Ano Meteorológico Típico (TMY2), a carta bioclimática, arquivos EPW e CVS, diagrama de ventos e o dia típico de projeto são os tratamentos mais comuns. Para Santa Maria - RS, algumas destas sistematizações já existiam, porém para um período de oito anos. O objetivo do estudo foi tratar e analisar dados climáticos para Santa Maria, complementando estudos anteriores, ampliando a base de dados para doze anos e atualizando seu tratamento. O estudo baseou-se em bibliografia científica e metodologias que vêm sendo empregadas por vários pesquisadores. Os resultados apontam maior desconforto por frio. A radiação solar é bem distribuída ao longo do ano, indicando aquecimento solar passivo, no inverno, e sombreamento, no verão. $\mathrm{O}$ arquivo TMY2 gerado no estudo tem comportamento similar ao TRY-INMET (2012) e apresenta diferenças mais significativas quando comparado ao SWERA. Observou-se a importância das orientações norte e nordeste, para aquecimento solar, e leste, para ventilação. Os métodos apresentados podem ser aplicados a outras localidades com dados horários disponíveis.

Palavras-chaves: Dados climáticos. Desempenho térmico. Projeto bioclimático. Santa Maria.

\begin{abstract}
Processing climatological data and making them available to building designers is of great importance for the thermal performance and energy efficiency of buildings. Test Reference Year, Typical Meteorological Year, bioclimatic chart, EPW and CSV files, wind speed and frequency roses and design day are the most used parameters. Before this study, there was already some systematization of the data available in Santa Maria - RS, however that was for a time range of only eight years. The aim of this study was to process and analyze the climatological data for Santa Maria over a twelve-year period. The method used was based on the scientific literature and followed methods developed and used by Brazilian research groups. The results for Santa Maria show greater discomfort in cold conditions. Direct solar radiation is well distributed throughout the year, indicating the use of passive solar heating in winter and shading in summer. For natural ventilation, the east wind direction should be given preference. The TMY2 file generated in this study is similar to the TRY-INMET (2012), but it presents more significant differences when compared with the SWERA file. The study highlighted the importance of north and northeast orientation for insolation and east direction for natural ventilation. The method presented can be applied in other cities that have available climatological data. Keywords: Climatological data. Thermal performance. Bioclimatic building design. Santa Maria - Brazil.
\end{abstract}

Recebido em 03/05/15 Aceito em 05/10/15

GRIGOLETTI, G. de C.; FLORES, M. G.; SANTOS, J. C. P. dos. Tratamento de dados climáticos de Santa Maria, RS, para análise de desempenho térmico de edificações. Ambiente Construído, Porto Alegre, v. 16, n. 1, p. 123-141, jan./mar. 2016. 


\section{Introdução}

A arquitetura bioclimática requer o conhecimento do clima local, sendo importante a disponibilização de dados climáticos para o projeto de edificações. Esse objetivo exige tratamento de dados que transformem a grande quantidade de registros de estações meteorológicas em ferramentas aplicáveis ao projeto (RORIZ, 2012a).

Apesar da disseminação de estações a partir da década de 1990 (com uma rede atual de mais de 600 estações automáticas que captam dados horários), a grande maioria das cidades brasileiras ainda não é contemplada com dados climáticos em um formato compatível com programas computacionais de avaliação termoenergética de edificações como o Energy Plus, desenvolvido pelo US Department of Energy ${ }^{1}$, e o Design Builder. Goulart, Lamberts e Firmino (1998) sistematizaram dados climáticos para as principais capitais brasileiras e disponibilizaram informações sobre dias típicos de verão e inverno, ano climático de referência, graus-dia e graus-hora, entre outros.

O Laboratório de Eficiência Energética em Edificações (LABORATÓRIO..., 2014), da Universidade Federal de Santa Catarina, disponibiliza arquivos climáticos para várias cidades brasileiras, no entanto os formatos são aqueles mais usados e não vêm acompanhados de análises mais específicas, como as propostas por Goulart e Lamberts (1993). Para Santa Maria, são disponibilizados dados no formato EPW (para uso nos programas Energy Plus e Design Builder), STAT e TRY (aqui indicado como TRY-Inmet) para um período de 8 anos, baseados em Roriz (2012a).

O tratamento de dados climáticos não se restringe somente a sua compilação e formatação. É necessário o controle de qualidade dos dados, ajustes e cálculos para encontrar as variáveis inexistentes. Estudos anteriores de Sattler (1989), Goulart (1993), Pereira (2004), Carlo e Lamberts (2005) e Roriz (2012a) contribuem para esse objetivo. No entanto, os métodos adotados pelos autores estão dispersos em vários documentos, o que pode dificultar sua divulgação e aplicação.

A climatologia, estudo científico do clima, analisa os padrões de variabilidade da atmosfera para um longo período (MENDONÇA; DANNIOLIVEIRA, 2007) e é importante para o desenvolvimento sustentável, incluindo a construção civil. O clima é caracterizado por variáveis objetivas como temperatura e umidade

${ }^{1}$ Departamento de Energia dos Estados Unidos. atmosférica, radiação solar, precipitação e ventos (POUEY, 2011).

As normais climatológicas são uma das formas mais divulgadas de dados climáticos. Segundo o Instituto Nacional de Meteorologia (INSTITUTO..., 2014, p. 7), normais são “[...] valores médios calculados para um período relativamente longo e uniforme, compreendendo no mínimo três décadas consecutivas [...]". O Inmet, em sua página eletrônica, disponibiliza dados coletados em suas estações meteorológicas. Porém, esse formato de dados, baseado em médias anuais e mensais das variáveis climáticas, são pouco úteis para o projeto de edificações, que depende de dados horários para simulação computacional. Os dados horários disponibilizados pelo Inmet são temperatura do ar, umidade relativa do ar, velocidade e direção de ventos, pressão atmosférica e radiação solar global horizontal.

Nos próximos itens são apresentadas limitações associadas a dados disponíveis, tratamento estatístico mais usuais, Ano Climático de Referência (TRY) e Ano Meteorológico Típico (TMY2), obtenção de dados sem registro, método de construção do dia típico de projeto e sistematização da velocidade e direção dos ventos.

\section{Limitação de dados climáticos}

Registros de dados climáticos podem conter dados não verossímeis ou não registrados, devido à falha humana, de equipamentos ou interrupção no fornecimento de energia. Os dados devem ser submetidos a uma análise para verificar sua qualidade e corrigir falhas. Pittigliani (2000) apresenta um método científico de verificação da qualidade de dados hidrometeorológicos composto de quatro testes:

(a) range (confere os limites climatológicos máximos e mínimos);

(b) step (avalia a diferença máxima entre valores de dois dados consecutivos);

(c) persistence (verifica a persistência de um mesmo valor em uma série temporal); $\mathrm{e}$

(d) spatial (realiza um exame espacial dos dados).

Segundo Loureiro (2003), quando o intervalo de dados nulos é maior do que $5 \mathrm{~h}$, é necessária a análise de dias anteriores e posteriores ao intervalo. Faz-se a interpolação dos dados, de modo a completar os dados nulos a partir dos referentes de mesmo horário e tendências de variações diárias. Para períodos maiores, segundo Roriz (2012b), é preferível adotar dados de um ano 
anterior que seja semelhante ao atual. Na situação em que as lacunas encontradas se estendam por vários dias consecutivos, segundo Guimarães e Carlo (2010), os tratamentos são considerados ineficientes, e os meses em questão são descartados da compilação dos arquivos climáticos.

Pode haver dificuldade de localização dos registros de dados, que, geralmente, é distante do ponto em que se pretende edificar. Segundo Roriz (2012a), há dados sobre radiação solar apenas para 216 cidades brasileiras. Para Santa Maria, há registro de radiação solar global horizontal, temperatura de ponto de orvalho e umidade relativa, sendo necessários cálculos analíticos para radiação solar direta e difusa e temperatura de bulbo úmido, entre outras variáveis, para gerar os arquivos Energy Plus Weather (EPW) e CSV (comma-separeted values), necessários para simulação computacional. Existem métodos de tratamento que permitem encontrar dados não medidos de forma direta (GOULART; LAMBERTS; FIRMINO, 1998).

\section{Tratamento estatístico de dados}

A análise estatística permite organizar um grande número de dados para maior compreensão dos fenômenos que eles representam. Entre as análises de tratamentos estatísticos, a medida de assimetria (indicador da forma de distribuição dos dados à direita ou esquerda), a curtose (indicador de altura ou achatamento da distribuição dos dados é igual a zero quando normal; positivo quando concentrados no centro, com pico elevado; e negativo, que indica que a distribuição é mais achatada ou os dados dispersos) e a correlação de Pearson (fornece uma medida do grau de correlação linear entre duas variáveis quantitativas) são importantes na compreensão do comportamento do clima, pois uma análise baseada apenas em médias pode ocultar informações úteis para o projeto de edificações (UNIVERSIDADE..., 2012).

\section{Ano Climático de Referência e Ano Meteorológico Típico}

O Energy Plus e o Design Builder adotam informações horárias para um ano. Os formatos mais adequados para simulação são o Ano Climático de Referência (TRY do inglês Test Reference Year) e o Ano Meteorológico Típico (TMY2, que é um aperfeiçoamento do TMY, do inglês Typical Meteorological Year) (LAMBERTS; DUTRA; PEREIRA, 2014). Para a construção do TRY, os anos que apresentam temperaturas médias mensais extremas (altas e baixas) são descartados até que reste um ano considerado representativo do período (GOULART, 1993; FERREIRA, 2006). O TMY2 consiste em 12 meses restantes da eliminação de meses atípicos, (diferente do TRY, que desconsidera o ano inteiro), não sendo um ano real, formado por 12 meses de anos diferentes.

Para simulações com o programa Energy Plus é necessário tratar e compilar o arquivo climático TRY ou TMY2 para o formato EPW. Esse formato consiste em dados tais como temperaturas de bulbo seco $\left({ }^{\circ} \mathrm{C}\right)$, temperatura de ponto de orvalho $\left({ }^{\circ} \mathrm{C}\right)$, umidade relativa $(\%)$, pressão atmosférica $(\mathrm{Pa})$, radiação solar (global, direta, difusa e infravermelha, expressa em $\mathrm{Wh} / \mathrm{m}^{2}$ ), iluminância (global, direta e do zênite, expressa em lux), direção do vento (graus), velocidade do vento (m/s), cobertura total do céu (em décimos), visibilidade $(\mathrm{km})$ e precipitação $(\mathrm{mm})$ (PEREIRA, 2004).

\section{Obtenção de dados sem registro: temperatura de bulbo úmido e radiação solar direta e difusa}

A temperatura de bulbo úmido está relacionada à de bulbo seco e à umidade relativa do ar. Quanto maior a diferença entre os dois tipos de bulbos, menor a umidade relativa. É possível encontrar a temperatura de bulbo úmido a partir de temperatura de bulbo seco, umidade relativa, temperatura de ponto de orvalho e pressão barométrica (PEREIRA, 2004).

Quanto à radiação solar direta normal e difusa horizontal, parte-se da radiação solar incidente sobre o topo da atmosfera terrestre, que depende da época do ano, do período do dia e da latitude (AYOADE, 1996; MARTINAZZO, 2004). Duffie e Beckman (1980) fundamentam a teoria para conversão de dados de horas de insolação em radiação solar. Pitta (2001) estudou métodos para cálculo da radiação solar a partir da cobertura de nuvens e da duração de brilho do sol, dados disponibilizados pelas estações meteorológicas. Martinazzo (2004) elaborou modelos de estimativas da radiação solar, fazendo um levantamento histórico dos modelos de previsão desse tipo de registro. Pereira (2004) desenvolveu procedimentos para a inserção de dados climáticos em programas computacionais de simulação energética.

Carlo e Lamberts (2005) elaboraram relatório de processamento de arquivos climáticos para simular o desempenho energético de edificações. $\mathrm{O}$ estudo apontou o método de Pitta (2001) como o mais adequado para a estimativa de variáveis ligadas à radiação solar global horizontal, como a radiação 
direta normal e difusa horizontal. Guimarães e Carlo (2010) desenvolveram arquivo climático para a simulação computacional de desempenho termoenergético usando as equações de Duffie e Beckmann (1980).

O estudo apoiou-se nesses autores para gerar dados que não são medidos de forma direta em estações meteorológicas.

\section{Dia Típico de Projeto}

Dia típico de projeto é uma metodologia de tratamento de dados utilizada no Brasil de acordo com duas abordagens: Sattler (1989) e Instituto de Pesquisas Tecnológicas do Estado de São Paulo (IPT) (AKUTSU; PEDROSO, 1987). Segundo Goulart e Lamberts (1993), uma das diferenças entre os dois métodos é que Sattler finaliza com um dia típico considerado teórico, e o IPT, um dia real. O primeiro consegue escolher, considerando as médias diárias de cada intervalo, o dia típico para cada nível com característica mais próxima aos valores médios. Outra distinção entre as metodologias é que, segundo o IPT, os períodos de verão e inverno são caracterizados pelos meses mais quentes e mais frios do ano. Já o trabalho de Sattler define os períodos a partir dos dias mais quentes e mais frios. Ambos os métodos utilizam a temperatura do ar como parâmetro básico para a caracterização de dias típicos.

O método de Sattler parte da probabilidade de ocorrência de valores de variáveis climáticas. São caracterizados dias típicos de verão e de inverno cujas ocorrências se dão segundo níveis de probabilidade $(2,5 \%, 5 \%, 10 \%)$. O dia típico é representado por dados horários de temperaturas de bulbo seco e de bulbo úmido (ou umidade relativa), radiação solar, direção e velocidade do vento (SATTLER, 1989).

\section{Velocidade e direção dos ventos e carta bioclimática}

O conhecimento da distribuição da orientação dos ventos permite a proteção do vento no clima frio e de aproveitamento de brisas frescas para épocas quentes. Os diagramas como rosa dos ventos indicam as probabilidades de ocorrência de vento e suas principais orientações e velocidades (LAMBERTS; DUTRA; PEREIRA, 2014).

Como forma de permitir uma melhor representação dos dados de ventos, o programa Analysis SOLAR, desenvolvido pelo Labeee (LABORATÓRIO..., 2014), oferece a possibilidade de obtenção da rosa dos ventos e contém a frequência de ocorrência e a velocidade média em cada estação do ano para oito orientações.

Os dados climáticos também podem ser apresentados em forma de carta bioclimática (GIVONI, 1992), construída sobre um diagrama psicométrico, com dados de temperaturas de bulbo seco e úmido, umidade absoluta e umidade relativa. Esse diagrama permite a análise do conforto térmico e das estratégias bioclimáticas mais adequadas ao clima local (KINSEL, 2009).

\section{Objetivo}

Este artigo objetiva o tratamento de dados climáticos para Santa Maria, RS, apresentando os métodos usados para gerar o TRY, o TMY2, o Dia Típico de Projeto, a sistematização dos dados de velocidade e direção do ar, e sua formatação para o programa Energy Plus. O estudo também contribui para a organização e disponibilização de métodos de tratamento de dados climatológicos de forma única, uma vez que, atualmente, estão dispersos em vários documentos. Os procedimentos descritos podem ser aplicados a qualquer conjunto de dados similares para outras localidades brasileiras, contribuindo para o esforço em busca de edificações adaptadas a seu contexto climático e, portanto, com maior eficiência energética.

\section{Método de tratamento de dados}

Com o auxílio da planilha eletrônica, submeteremse os dados das variações de temperatura de bulbo seco e de ponto de orvalho, umidade relativa e velocidade do ar, pressão atmosférica, radiação global horizontal e precipitação a medidas estatísticas descritivas para o período compreendido entre os anos de 2002 e $2013^{2}$.

\section{Fontes dos dados}

Os dados foram obtidos nas estações meteorológicas situadas em Santa Maria e registrados pelo Inmet, cujas medições horárias compreendem janeiro de 2002 a dezembro de 2013, e na Base Aérea de Santa Maria (BASM) (altitude $=95 \mathrm{~m}$, latitude $=-29,7^{\circ}$, longitude $=$ $\left.53,7^{\circ}\right)$

As variáveis horárias disponibilizadas pelo Inmet são:

(a) temperatura de bulbo seco;

${ }^{2}$ Roriz, por correio eletrônico em setembro de 2012, declarou ser admissível desenvolver estudos com uma base de dados limitada, uma vez que não existem dados disponíveis para os 30 anos padronizados pela Organização Meteorológica Mundial. 
(b) temperatura de ponto de orvalho;

(c) umidade relativa;

(d) radiação solar global horizontal;

(e) pressão atmosférica; e

(f) velocidade e direção dos ventos e precipitação.

Os dados disponibilizados são brutos, e as informações são em horário UTC (para o horário oficial de Brasília, é preciso subtrair três horas). Falhas decorrentes de problemas nos sensores ou sinal de satélite estão identificadas pela palavra NULL.

Calcularam-se e ajustaram-se informações, conforme as referências apresentadas na introdução deste artigo, que possuíam algumas limitações, como distorções e ausências em registros de dados, e a falta de variáveis como a temperatura de bulbo úmido e a radiação direta normal, difusa horizontal, extraterrestre global e extraterrestre direta normal.

\section{Controle de qualidade dos dados}

Para o controle de qualidade dos dados, usaram-se dois testes, o range, cujos limites mínimo e máximo para as variáveis analisadas são apresentados na Tabela 1, e o step, cujo intervalo máximo é apresentado na Tabela 2 (PITTIGLIANI, 2000).

Para a série histórica dos dados horários, eliminaram-se as informações que não eram referentes às horas inteiras e efetuou-se a verificação dos dados ausentes. Para o intervalo de dados ausentes maior do que $5 \mathrm{~h}$, efetuou-se a análise de dias anteriores e posteriores. Os dados faltantes assumiram referentes com mesmo horário e tendência das variações. Já para períodos maiores foram adotados dados de outro ano que fosse semelhante àquele que apresentou as faltas. Em casos de lacunas que se estenderam por vários dias consecutivos, os meses em questão foram descartados da compilação dos arquivos climáticos. Desconsiderou-se o mês de julho de 2011, por exemplo, pois todo o mês estava com dados nulos.

\section{Análise estatística dos dados}

A análise estatística compreendeu dados entre 2002 e 2013 para as variáveis temperatura de bulbo seco, temperatura de ponto de orvalho, umidade relativa do ar, pressão atmosférica, velocidade do vento, radiação solar global horizontal e precipitação média. Resultados descritivos gerais e mensais das variáveis baseiamse em análises estatísticas para média, confiança, valores mínimos e máximos observados, variância, desvio padrão, coeficiente de variação, assimetria, curtose e correlação de Pearson. O resultado descritivo geral e de comportamento mensal considerou, no período estudado de 12 anos $105.120 \mathrm{~h}$, gerando 4.382 médias diárias, submetidas às análises.

Tabela 1 - Limites climatológicos adotados no teste de range

\begin{tabular}{lccc}
\hline Parâmetros meteorológicos & Unidade & $\begin{array}{c}\text { Limite climatológico } \\
\text { mínimo }\end{array}$ & $\begin{array}{c}\text { Limite climatológico } \\
\text { máximo }\end{array}$ \\
\hline Umidade relativa do ar & $\%$ & 0 & 103 \\
Temperatura média do ar & ${ }^{\circ} \mathrm{C}$ & -14 & 45 \\
Velocidade do vento & $\mathrm{m} / \mathrm{s}$ & 0 & 35 \\
Direção do vento & $\mathrm{o}$ & 0 & 360 \\
Precipitação & $\mathrm{mm}$ & 0 & 130 \\
Radiação solar & $\mathrm{W} / \mathrm{m}^{2}$ & -1 & 1.355 \\
\hline
\end{tabular}

Fonte: adaptado de Pittigliani (2000, p. 1531).

Tabela 2 - Limites máximos adotados no teste step

\begin{tabular}{lcc}
\hline \multicolumn{1}{c}{ Parâmetros meteorológicos } & Unidade & $\begin{array}{c}\text { Limite máximo para a diferença entre } \\
\text { dois dados consecutivos }\end{array}$ \\
\hline Umidade relativa do ar & $\%$ & 30 \\
Temperatura média do ar & ${ }^{\circ} \mathrm{C}$ & 7 \\
Velocidade dos ventos & $\mathrm{m} / \mathrm{s}$ & 40 \\
Direção dos ventos & $\mathrm{graus}$ & 360 \\
Precipitação & $\mathrm{mm}$ & 130 \\
Radiação solar & $\mathrm{W} / \mathrm{m}^{2}$ & 600 \\
\hline
\end{tabular}

Fonte: adaptado de Pittigliani (2000, p. 1530). 


\section{TRY e TMY2}

Para a geração do TRY aplicou-se a metodologia descrita por Goulart (1993). Os procedimentos consistiram na manipulação de uma planilha eletrônica, onde, primeiramente, geraram-se as médias mensais para o período de anos disponível. Depois, os meses foram classificados em ordem de importância, para o cálculo de energia, com anotação dos que apresentavam temperatura do ar mais quente e mais fria. Após a análise dos 12 meses, repetiu-se a sequência, porém invertendo-se o sentido da análise. Ou seja, dos meses quentes passou-se aos frios e vice-versa, sucessivamente. $\mathrm{O}$ ano mais quente e o mais frio foram anotados. $\mathrm{O}$ processo seguiu com anotações dos anos em que ocorreram os extremos, os quais foram eliminados. O método continuou a se repetir até que restasse somente 1 ano: o TRY, contendo valores de temperatura e umidade relativa das $8.760 \mathrm{~h}$, entre outras variáveis.

Compilaram-se os registros em um formato padronizado para adequarem-se aos programas de simulação de desempenho termoenergético de edificações. O TRY contém as seguintes variáveis: temperaturas de bulbo seco, bulbo úmido e de ponto de orvalho, direção e velocidade do vento, pressão barométrica, quantidade e tipo de nuvens, e variáveis relacionadas à radiação solar. A ausência de alguns dados horários e de variáveis tornou necessária a utilização de cálculos para completar as informações referentes à temperatura de bulbo úmido e variáveis relacionadas à radiação solar.

Para definir o TMY2, primeiramente, geraram-se as médias mensais para o período de anos disponível. Em seguida, obtiveram-se as médias das médias mensais. Depois, identificaram-se e classificaram-se os meses mais quentes e mais frios. Por fim, eliminaram-se os meses que possuíam as médias mensais maiores (mais quente) e menores (mais frio). Esse processo se repetiu até que restassem apenas 12 meses.

\section{Dia típico de projeto}

A análise dos dados para Santa Maria usou a abordagem proposta por Sattler (1989), conforme Goulart (1993), pois resulta em dias com amplitude de temperatura próxima à média e com maior frequência de ocorrência. Para gerar o dia típico de projeto, as temperaturas médias diárias foram ordenadas crescentemente (Tabela 3). Destacou-se o conjunto de $15 \%$ do número total de dias com temperaturas médias diárias mais altas, bem como os dias de média diária mais baixa (SATTLER, 1989).

Em 12 anos de dados disponíveis (2002-2013), em um total de 4.382 médias diárias, foram encontrados 657 dias de temperatura média mais alta e 657 dias de temperatura média mais baixa.

Em 12 anos houve $3.400(295 \times 11+155)$ dias quentes e $2.148(179 \times 12)$ dias frios. Reordenaramse os 3.400 valores de dias quentes e determinaram-se os níveis de probabilidade $2,5 \%$, $5 \%$ e $10 \%$ (temperaturas médias extremas ao longo de 85,170 e 340 dias). Da mesma forma, reordenaram-se os 2.148 dias frios também, determinando-se os níveis de probabilidade de $2,5 \%, 5 \%$ e $10 \%$ quando as temperaturas médias se excederam em 54, 108 e 215 dias.

A partir do dia de referência achado para cada percentil, selecionou-se $0,5 \%$ dos dias cujas temperaturas médias foram logo acima e $0,5 \%$ dos que tiveram a média imediatamente abaixo, representando $1 \%$ do total de dias do período de verão. Por exemplo, se, para o período de 3.400 dias quentes, selecionaram-se 34 dias, 17 estão acima do dia de referência e 17 estão abaixo. O mesmo processo ocorreu com os dias frios. Para o período de 2.148 dias frios, as médias das temperaturas horárias de 21 dias determinaram as temperaturas horárias de cada nível dos dias típicos de inverno, selecionando-se 20 dias, estando 10 deles acima do dia de referência e os outros 10 abaixo.

Tabela 3 - Tabela com as temperaturas médias ordenadas crescentemente

\begin{tabular}{c|c}
\hline Data & TBS $^{\mathbf{~}} \mathbf{C}$ \\
\hline 08-JUN-2012 & 3,87 \\
25-JUL-2009 & 3,91 \\
29-JUL-2007 & 4,41 \\
\hline \multicolumn{2}{|c}{$\ldots$} \\
\hline 19-FEV-2012 & 31,02 \\
03-FEV-2010 & 32,76 \\
25-DEZ-2012 & 33,20 \\
\hline
\end{tabular}

128 Grigoletti, G. de C.; Flores, M. G.; Santos, J. C. P. dos. 
Também se calcularam as médias horárias dos parâmetros climáticos dos dias situados nos intervalos, para cada nível, definindo-se os dias típicos de verão e de inverno. Para cada dia típico, listaram-se os valores horários das temperaturas de bulbo seco e bulbo úmido (ou umidade relativa), radiação solar global, direção e velocidade do vento.

\section{Velocidade e direção dos ventos}

Para a análise dos dados de ventos, usou-se o programa Analysis SOL-AR, que gera a frequência de ocorrência dos ventos e velocidade média para cada estação do ano em oito orientações (N, NE, L, SE, S, SO, O, NO). Essas análises foram feitas para os arquivos de TRY e TMY2 gerados para cidade de Santa Maria.

\section{Formatação de dados}

Os programas de simulação exigem formatos distintos. Para formatar os dados, utilizaram-se planilhas eletrônicas fornecidas pelo Laboratório de Eficiência Energética da Universidade Federal de Viçosa (Latecae). O Latecae trabalha com duas planilhas: Ashrae (AMERICAN..., 2001) e Pereira (2004). Para a escolha da planilha, analisou-se a temperatura de ponto de orvalho segundo Ashrae e
Pereira, comparando-a com dados do Inmet Ambas ficaram com resultados muito próximos das medidas na estação. Foi, então, escolhida a planilha de Ashrae, em função de ser uma metodologia mais consolidada. Para o cálculo da temperatura de bulbo úmido aplicou-se a metodologia de Pereira (2004), por sua baixa complexidade.

Os Quadros 1 e 2 indicam os formatos de planilhas para arquivos com extensão CSV e EPW, compatíveis com os programas Analysis SOL-AR e Energy Plus respectivamente, indicando a ordem de apresentação das variáveis e variáveis mínimas exigidas.

\section{Cálculo das variáveis sem registro}

A temperatura de bulbo úmido e a radiação solar direta e difusa não estavam disponíveis no conjunto de dados, sendo necessário utilizar modelos analíticos para sua estimativa. Calcularam-se, além dessas duas variáveis citadas, a entalpia, a umidade e a densidade do ar, para gerar o arquivo com extensão CSV.

A temperatura de bulbo úmido foi calculada com o auxílio de uma planilha eletrônica, com base na metodologia utilizada por Pereira (2004), conforme indicado na Tabela 4.

Quadro 1 - Referência para os arquivos de extensão CSV

\begin{tabular}{|c|c|c|c|c|c|c|c|c|}
\hline Mês & Dia & Hora & $\begin{array}{l}\mathrm{TBS} \\
\left\{{ }^{\circ} \mathrm{C}\right\}\end{array}$ & $\begin{array}{l}\mathrm{TBU} \\
\left\{{ }^{\circ} \mathrm{C}\right\}\end{array}$ & $\begin{array}{c}\mathrm{Td} \\
\left\{{ }^{\circ} \mathrm{C}\right\}\end{array}$ & $\begin{array}{r}\mathrm{P} \\
\text { atm }\end{array}$ & ấa & $\begin{array}{c}\text { Umidade } \\
\text { relativa } \\
\{\%\} \\
\end{array}$ \\
\hline $\begin{array}{l}\text { Densidade } \\
\text { do ar }\end{array}$ & Entalpia & & $\begin{array}{l}\text { Velocidade } \\
\text { dos ventos } \\
\qquad\{\mathrm{m} / \mathrm{s}\}\end{array}$ & $\begin{array}{c}\text { Direção do } \\
\text { vento }\{\text { Grau }\}\end{array}$ & \multicolumn{2}{|c|}{$\begin{array}{c}\text { Cobertura } \\
\text { total de } \\
\text { nuvens } \\
\left\{\mathrm{Wh} / \mathrm{m}^{2}\right\}\end{array}$} & \multicolumn{2}{|c|}{$\begin{array}{c}\text { Radiação global } \\
\text { horizontal } \\
\text { extraterrestre } \\
\left\{\mathrm{Wh} / \mathrm{m}^{2}\right\} \\
\end{array}$} \\
\hline \multicolumn{2}{|c|}{$\begin{array}{c}\text { Radiação global } \\
\text { horizontal }\left\{\mathrm{Wh} / \mathrm{m}^{2}\right\}\end{array}$} & \multicolumn{2}{|c|}{$\begin{array}{c}\text { Radiação direta } \\
\left\{\mathrm{Wh} / \mathrm{m}^{2}\right\}\end{array}$} & \multicolumn{2}{|c|}{$\begin{array}{c}\text { Radiação direta } \\
\text { normal }\left\{\mathrm{Wh} / \mathrm{m}^{2}\right\}\end{array}$} & \multicolumn{3}{|c|}{$\begin{array}{c}\text { Radiação difusa horizontal } \\
\left\{\mathrm{Wh} / \mathrm{m}^{2}\right\}\end{array}$} \\
\hline
\end{tabular}

Quadro 2 - Referência para os arquivos de extensão EPW

\begin{tabular}{|c|c|c|c|c|c|c|c|}
\hline Date & HH:MM & $\begin{array}{c}\text { Data } \\
\text { source }\end{array}$ & $\begin{array}{c}\text { DryBul } \\
\mathrm{b}\{\mathrm{C}\}\end{array}$ & $\begin{array}{c}\text { DewPoint } \\
\{\mathrm{C}\}\end{array}$ & $\begin{array}{c}\text { RelHum } \\
\{\%\}\end{array}$ & $\begin{array}{c}\text { Atmos } \\
\text { Pressure }\{\mathrm{Pa}\}\end{array}$ & $\begin{array}{c}\text { ExtHorzRad } \\
\{\mathrm{Wh} / \mathrm{m} 2\}\end{array}$ \\
\hline $\begin{array}{c}\text { GloHorzRad } \\
\{\mathrm{Wh} / \mathrm{m} 2\}\end{array}$ & $\begin{array}{c}\text { DirNormRad } \\
\{\mathrm{Wh} / \mathrm{m} 2\}\end{array}$ & $\begin{array}{c}\text { DifHorzRad } \\
\text { (Wh/m2 }\}\end{array}$ & WindDir $\{\mathrm{deg}\}$ & $\begin{array}{c}\text { WindSpd } \\
\{\mathrm{m} / \mathrm{s}\}\end{array}$ & $\begin{array}{c}\text { PrecipWtr } \\
\{\mathrm{mm}\}\end{array}$ \\
\hline
\end{tabular}

Tabela 4 - Exemplo da planilha de cálculo da TBU

\begin{tabular}{|c|c|c|c|c|c|}
\hline To & $\begin{array}{c}g=0,00066 x \\
\text { PA }\end{array}$ & & $\begin{array}{c}d=4098 x \\
e /(T o+273,3)^{2}\end{array}$ & & $\begin{array}{c}\mathbf{T u}=[(\mathbf{g} \mathbf{x} \mathbf{T})+(\mathbf{d} \\
\quad \mathbf{x} \mathbf{T o})] /(\mathbf{g}+\mathbf{d})\end{array}$ \\
\hline $\begin{array}{l}12.30 \\
11.90\end{array}$ & $\begin{array}{c}G \\
6.64 \\
6.64\end{array}$ & $\begin{array}{c}e \\
1.43 \\
139\end{array}$ & $\begin{array}{c}D \\
0.07 \\
0.07\end{array}$ & $\begin{array}{c}\mathrm{e} /(\mathrm{To}+273,3) 2 \\
1.76 \mathrm{E}-05 \\
171 \mathrm{E}-05\end{array}$ & $\begin{array}{c}\text { TBU_Final } \\
13.09 \\
12.69\end{array}$ \\
\hline$\ldots$ & $\ldots$ & & $\ldots$ & $\ldots$ & $\ldots$ \\
\hline
\end{tabular}

Fonte: adaptado de Pereira (2004). 
Para variáveis relacionadas à radiação solar, aplicaram-se os procedimentos descritos por Pitta (2001), Martinazzo (2004), Pereira (2004) e Duffie e Beckmann (1980). A Tabela 5 ilustra parte da planilha eletrônica para a organização dos dados necessários para o cálculo das variáveis não medidas de forma direta, indicando a ordem e a forma de apresentação dos dados.

Foi necessária a análise da consistência dos dados de temperatura de bulbo úmido e da radiação global horizontal. A temperatura de bulbo úmido não pode ultrapassar a de bulbo seco. A radiação global horizontal não pode ser maior do que a radiação extraterrestre global horizontal. Segundo Guimarães e Carlo (2010), essas inconsistências devem ser tratadas. Em caso de a TBU ser maior do que a TBS, igualam-se os registros. Se a radiação global horizontal for maior do que a extraterrestre global horizontal, também se igualam as variáveis.

Após o tratamento ocorreu a compilação dos dados. Para gerar o EPW, com o auxílio de uma planilha eletrônica, criou-se um arquivo CSV. Com o aplicativo Weather Statistics and Conversions, programa auxiliar do pacote do Energy Plus, inseriu-se o arquivo CSV para convertê-lo em EPW. Também se gerou o arquivo TRY obtido com o aplicativo Psychros, para uso no programa Analysis Bio, para geração da carta bioclimática.

Os arquivos TRY e TMY2 gerados neste trabalho foram comparados com os arquivos já existentes para Santa Maria, ou seja, o TRY gerado por Roriz (2012a), aqui chamado de TRY- Inmet (SCHELLER et al., 2015), e o arquivo denominado Solar and Wind Energy Resource Assessment $\left(\right.$ SWERA $\left.^{3}\right)$. Essa análise é apresentada com maior detalhamento apenas para a variável TBS, por esta ser a referência para gerar os arquivos TRY e TMY2.

\section{Resultados}

\section{Temperatura de bulbo seco e umidade relativa do ar}

A Figura 1 demonstra que a distribuição é moderadamente assimétrica para a direita, com concentração de valores mais elevados de temperatura, ou seja, o clima da localidade apresenta temperaturas com tendência acima da média.
O coeficiente de variância, a variância e o desvio padrão foram menores no mês de janeiro, indicando temperaturas elevadas no decorrer desse mês para todos os horários do dia. Entretanto, a maior temperatura registrada no período ocorreu no mês de dezembro $\left(33,2^{\circ} \mathrm{C}\right)$.

O menor valor de temperatura média foi no mês de julho, mês mais frio do período. Porém, foi no mês de junho que se obteve o menor valor registrado, $3,87^{\circ} \mathrm{C}$. O mês de agosto teve os maiores valores de variância, desvio padrão, devido a uma grande dispersão da média. Esse mês é caracterizado por ondas de calor frequentes, o que vai ao encontro da análise estatística. A maior amplitude entre temperatura máxima e temperatura mínima foi em julho, com temperatura mínima de $3,91{ }^{\circ} \mathrm{C}$ e máxima de $27,15{ }^{\circ} \mathrm{C}$. $\mathrm{O}$ mês de fevereiro apresentou os valores mais bem distribuídos em relação à média.

Para análise da temperatura no período de anos disponíveis usou-se como referência os limites da zona de conforto propostos por Givoni (1992), ou seja, intervalo da zona de conforto entre $18^{\circ} \mathrm{C}$ e 29 ${ }^{\circ} \mathrm{C}$ (Figura 2). As temperaturas ultrapassam o limite inferior de forma mais contundente do que o limite superior. Isso é um indicativo de que as condições de frio são mais desfavoráveis que as condições de calor.

Para a umidade relativa do ar, a distribuição foi moderadamente assimétrica, com assimetria acentuando-se para a direita, indicando maior concentração em valores elevados de umidade. A média mais baixa de umidade relativa do ar ocorreu no mês de dezembro, com $70,80 \%$, que também apresenta média de temperatura mais elevada. Já a média de umidade relativa mais elevada ocorreu no mês de junho (83,23\%). A umidade relativa do ar mais elevada do período ocorreu nos meses de julho e setembro, ambos com $97,87 \%$. O mês com a menor umidade foi setembro, com $33,87 \%$, sendo esse o mês com a maior variação de umidade do período $(64 \%)$.

A umidade relativa do ar não possui valores de desvio padrão e de coeficiente de variação significativos, o que demonstra que seus resultados se encontram, na maioria, próximos à média.

\footnotetext{
${ }^{3}$ SWERA é uma base de dados gerenciada pelo Programa das Nações Unidas para o Meio Ambiente iniciada em 2001, de acesso livre, com o objetivo de incentivar o uso de tecnologias mais sustentáveis (SWERA, 2014; SCHELLER et al., 2015).
} 
Tabela 5 - Planilha com valores de radiação global diária e radiação horária

\begin{tabular}{|c|c|c|c|c|c|c|c|c|}
\hline $\begin{array}{c}\text { Mês } \\
(m)\end{array}$ & $\begin{array}{c}\text { Dia } \\
(i)\end{array}$ & $\begin{array}{l}\text { Dia } \\
\text { ano } \\
(n)\end{array}$ & $\begin{array}{c}\text { Declinação } \\
(\delta)\end{array}$ & $\begin{array}{l}\text { Hora } \\
\text { solar }\end{array}$ & 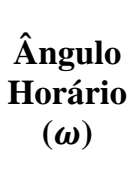 & $\begin{array}{c}\text { Ângulo } \\
\text { pôr } \\
\text { do sol } \\
\left(w_{s}\right)\end{array}$ & $\begin{array}{c}\text { Radiação } \\
\text { global } \\
\text { diária }(H)\end{array}$ & $\begin{array}{c}\text { Radiação } \\
\text { horária } \\
\text { I W.h/m } / \mathbf{m}^{2}\end{array}$ \\
\hline 1 & 1 & 1 & -23.01 & $4: 22$ & -114.5 & 104.01 & 7279 & 0.00 \\
\hline 1 & 1 & 1 & -23.01 & $5: 22$ & -99.5 & 104.01 & 7279 & 36.37 \\
\hline 1 & 1 & 1 & -23.01 & $6: 22$ & -84.5 & 104.01 & 7279 & 179.94 \\
\hline
\end{tabular}

Fonte: adaptado de Pitta (2001).

Figura 1 - Histograma da média diária de temperatura de bulbo seco

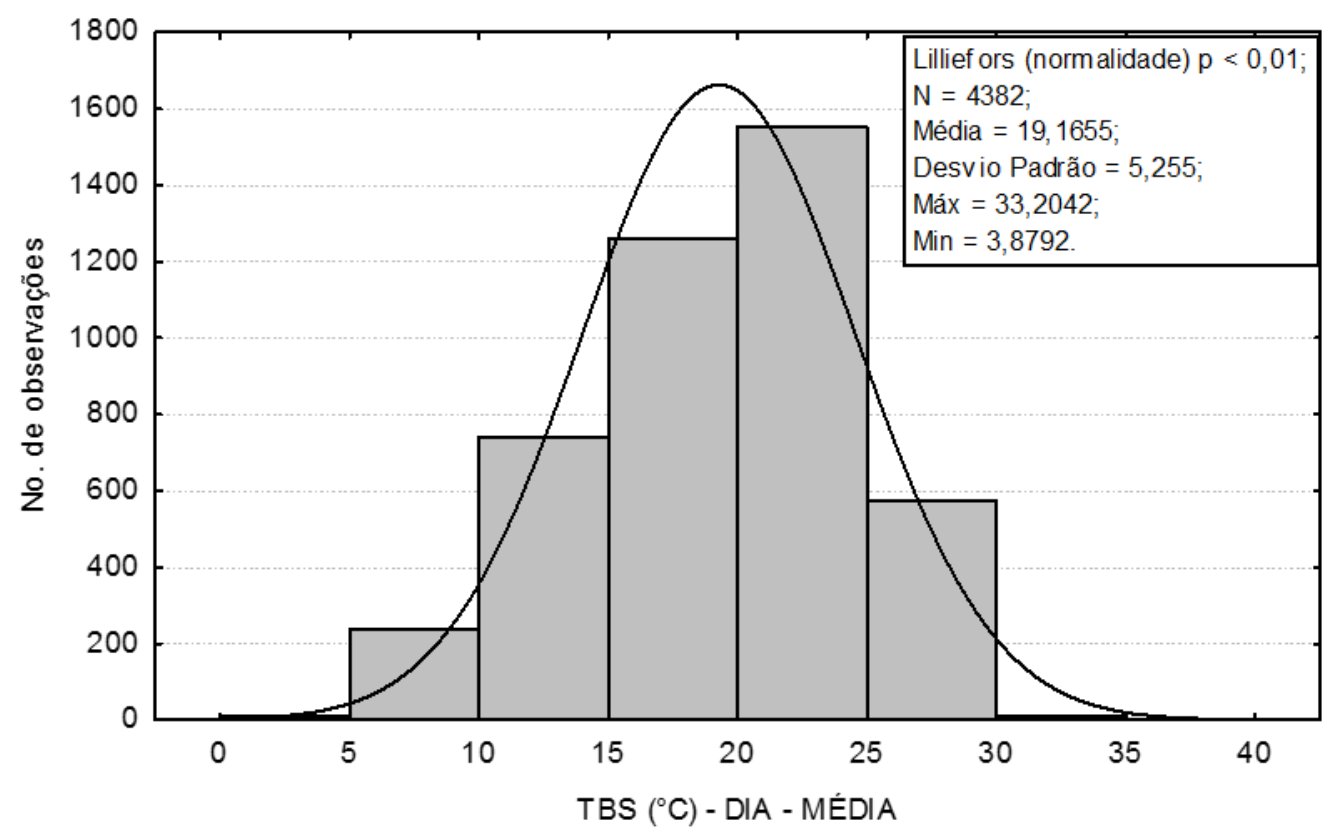

N (4382); Média $\left(19,16^{\circ} \mathrm{C}\right)$; Conf. $-95 \%\left(19,01^{\circ} \mathrm{C}\right)$; Conf. + 95\% $\left(19,32^{\circ} \mathrm{C}\right)$; Mínimo $\left(3,87^{\circ} \mathrm{C}\right)$; Máximo $\left(33,20^{\circ} \mathrm{C}\right)$; Var. (27,61); Desvio $(5,25)$; Coef .Var. \% $(27,41)$; Assimetria (-0,41); Curtose (- 0,50)

Figura 2 - Médias diárias da temperatura e limites de conforto de Givoni

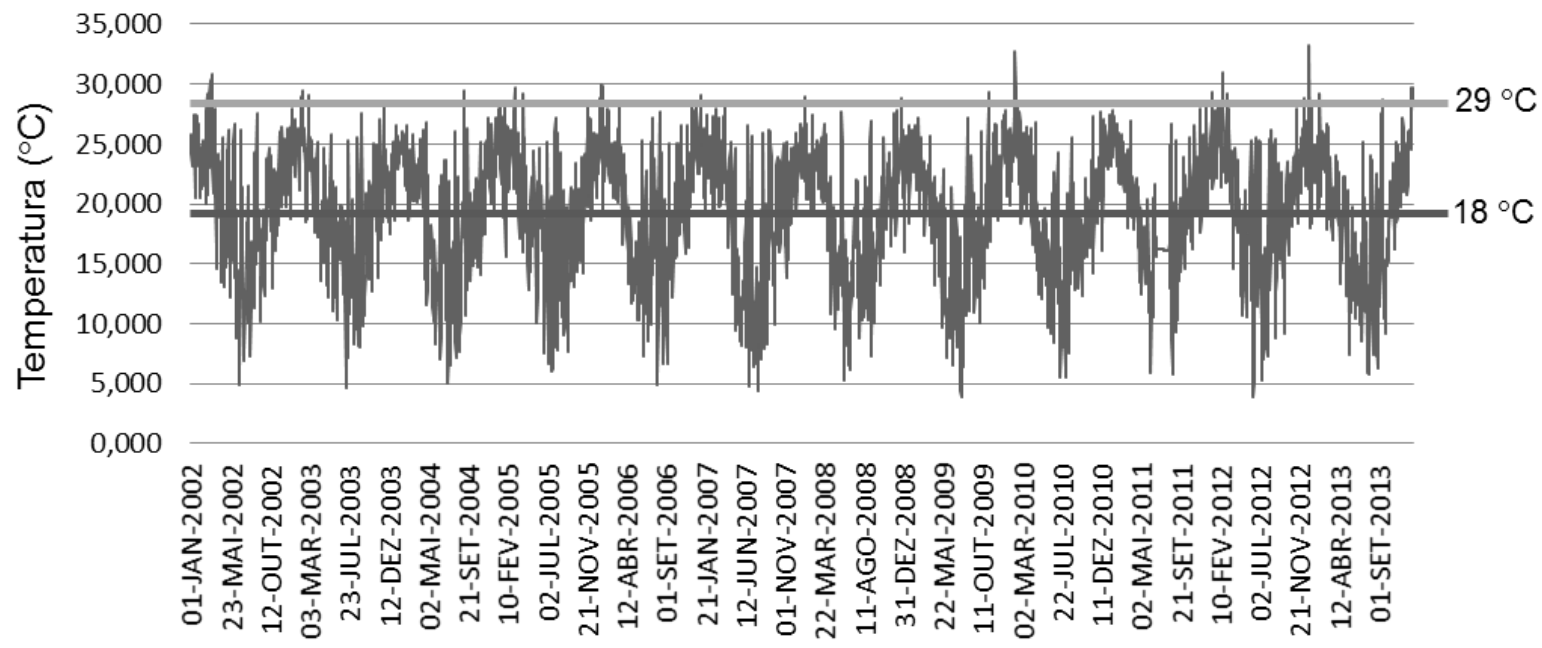




\section{Velocidade dos ventos}

Os ventos possuem uma distribuição moderadamente assimétrica à esquerda. As velocidades máxima e mínima dos ventos ocorreram no mês de agosto, $7,38 \mathrm{~m} / \mathrm{s}$ e $0,00 \mathrm{~m} / \mathrm{s}$ respectivamente. A média da velocidade dos ventos mais elevada do período foi no mês de novembro, com $2,46 \mathrm{~m} / \mathrm{s}$, e o mês com a menor velocidade foi abril, com $1,72 \mathrm{~m} / \mathrm{s}$. A velocidade dos ventos possui valores de desvio padrão e de coeficiente de variação altos, no entanto esse comportamento é normal para essa variável. Um parâmetro importante para o projeto de edificações é, além da velocidade do vento, sua direção predominante, análise apresentada juntamente com o TRY.

\section{Radiação solar global horizontal}

Os dados gerais de radiação solar global horizontal apresentaram achatamento (curtose negativa). A distribuição é moderadamente assimétrica, tendendo para a direita. O valor da radiação global horizontal máxima foi registrado no mês de dezembro, com $665,23 \mathrm{Wh} / \mathrm{m}^{2}$, ocorrendo nesse mês também a temperatura do ar mais elevada do período, $33,2^{\circ} \mathrm{C}$. O registro do menor valor médio da radiação solar global horizontal foi em junho, que apresenta o menor registro de temperatura do ar, $3,87^{\circ} \mathrm{C}$. Em relação à assimetria mensal, todos os meses tiveram valores negativos, ou seja, tendência de valores mais elevados para a radiação solar em relação à média.

\section{Relação entre as variáveis}

A partir dos dados constantes na Tabela 6, para correlações de Pearson para algumas variáveis analisadas, e pela Figura 3 observa-se forte associação (valores maiores que 0,6) entre temperatura de bulbo seco e temperatura do ponto de orvalho e uma associação inversa entre pressão atmosférica e temperatura de bulbo seco e temperatura de ponto de orvalho, expressando a coerência dos resultados.

Tabela 6 - Correlações das variáveis de Pearson

\begin{tabular}{lcccc}
\hline & TBS & TPO & UR & $\begin{array}{c}\text { Radiação } \\
\text { global hor. }\end{array}$ \\
\hline TBS $\left({ }^{\circ} \mathrm{C}\right)$ - dia - média & 1,000 & & & \\
TPO $\left({ }^{\circ} \mathrm{C}\right)$ - dia - média & 0,878 & 1,000 & & \\
UR $(\%)$ - dia - média & $-0,436$ & 0,034 & 1,000 & \\
Radiação global hor. $\left(\mathrm{wh} / \mathrm{m}^{2}\right)-$ dia - média & 0,433 & 0,151 & $-0,645$ & 1,000 \\
\hline
\end{tabular}

Figura 3 - Diagrama de dispersão - TPO $\left({ }^{\circ} \mathrm{C}\right) \times \operatorname{TBS}\left({ }^{\circ} \mathrm{C}\right)$

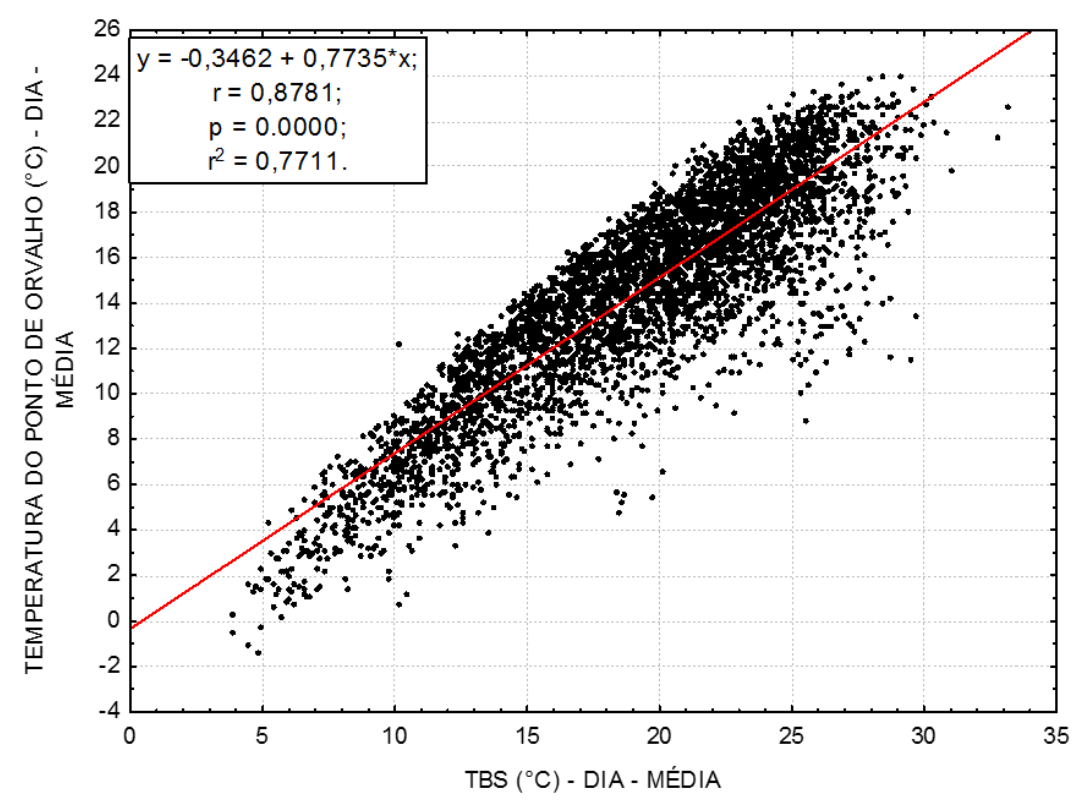

$r=$ coeficiente de correlação de Pearson; $p=$ significância da correlação; $r^{2}=$ coeficiente de determinação da equação, ou seja, quanto da variável Y é explicada pela variável $\mathrm{X}$. 
A radiação solar global horizontal tem uma associação inversa com a umidade relativa do ar em função de seu valor negativo e com a temperatura de bulbo seco com valor menor. A correlação de Pearson demonstra forte correlação com a umidade relativa do ar, de forma inversa, e baixa correlação com a temperatura de bulbo seco, como se observa na Figura 4. Esses resultados demonstram a coerência das relações das variáveis que são usadas para cálculos das variáveis que não foram medidas na estação meteorológica.

\section{Análise dos arquivos TRY e TMY2 e da carta bioclimática para Santa Maria}

Para o período de anos disponível, o TRY é representado pelo ano de 2003, conforme indicado na Tabela 7 (linha em destaque), coincidindo com o ano encontrado por Roriz (2012a) para o período entre 2002 e 2010. Esse resultado pode demonstrar a estabilidade do comportamento climático dos intervalos de anos estudados.

Figura 4 - Diagrama de dispersão - Radiação global x TBS $\left({ }^{\circ} \mathrm{C}\right)$

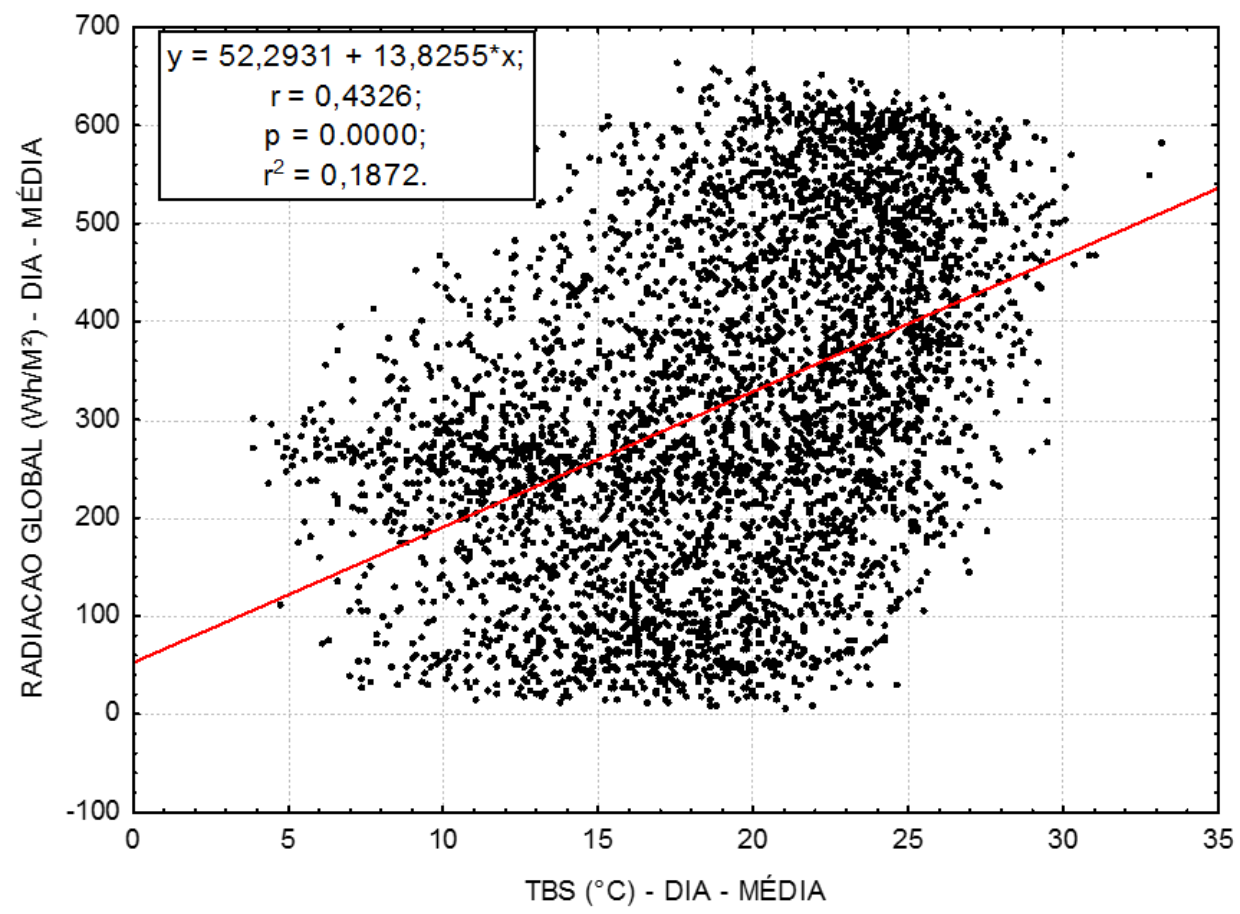

$r=$ coeficiente de correlação de Pearson; $\mathrm{p}=$ signifícância da correlação; $\mathrm{r}^{2}=$ coefíciente de determinação da equação, ou seja, quanto da variável Y é explicada pela variável X.

Tabela 7 - TRY, temperaturas médias mais quentes e mais frias grifadas, em ${ }^{\circ} \mathrm{C}$

\begin{tabular}{ccccccccccccc}
\hline Ano/mês & jan & fev & mar & abr & mai & jun & jul & ago & set & out & nov & dez \\
\hline 2002 & 24,7 & 23,0 & 25,2 & 19,7 & 18,2 & 14,6 & 13,6 & 16,2 & 16,3 & 20,5 & 21,8 & 23,5 \\
\hline 2003 & 24,9 & 24,8 & 22,2 & 18,6 & 16,6 & 15,7 & 13,6 & 13,4 & 15,8 & 19,8 & 21,2 & 21,4 \\
\hline 2004 & 24,4 & $\mathbf{2 2 , 9}$ & 22,2 & 21,0 & 14,2 & 15,4 & 13,2 & 15,0 & 18,0 & 18,1 & 20,6 & 23,2 \\
\hline 2005 & 25,3 & 23,7 & 23,2 & 18,8 & 17,9 & 17,7 & 15,1 & 16,6 & $\mathbf{1 4 , 3}$ & 17,9 & 21,7 & $\mathbf{2 2 , 8}$ \\
\hline 2006 & 25,0 & 23,8 & 22,7 & 18,8 & $\mathbf{1 3 , 5}$ & 15,0 & 16,5 & 14,5 & 15,2 & 20,2 & 20,7 & 24,9 \\
\hline 2007 & 24,2 & 24,1 & 23,6 & 20,6 & 14,2 & 13,9 & 11,0 & $\mathbf{1 3 , 1}$ & 18,7 & 20,2 & $\mathbf{2 0 , 3}$ & 23,4 \\
\hline 2008 & 23,7 & 23,2 & 22,4 & $\mathbf{1 8 , 1}$ & 15,6 & $\mathbf{1 1 , 8}$ & 15,9 & 14,4 & 15,0 & 18,7 & 22,2 & 23,4 \\
\hline 2009 & $\mathbf{2 3 , 1}$ & 23,8 & $\mathbf{2 2 , 2}$ & 19,1 & 16,5 & $\mathbf{1 1 , 8}$ & $\mathbf{1 0 , 5}$ & 16,2 & 15,8 & 18,4 & 22,8 & 23,5 \\
\hline 2010 & 24,2 & 25,5 & 23,3 & 19,0 & 15,6 & 14,1 & 13,3 & 13,8 & 16,5 & $\mathbf{1 7 , 7}$ & 20,3 & 23,3 \\
\hline 2011 & 25,4 & 24,0 & 22,0 & 19,2 & 15,3 & 14,1 & & 15,4 & 16,5 & 19,0 & 22,1 & 23,0 \\
\hline 2012 & 25,3 & 25,9 & 22,6 & 18,5 & 17,5 & 14,3 & 12,8 & 19,3 & 17,5 & 20,4 & 23,3 & 24,7 \\
\hline 2013 & 23,4 & 23,6 & 20,6 & 19,2 & 15,4 & 13,5 & 13,5 & 13,2 & 17,4 & 19,3 & 22,5 & 25,2 \\
\hline
\end{tabular}

Nota: na tabela, TRY em destaque, temp. médias mais quentes em cinza e temp. médias mais frias em negrito. 
A Tabela 8 apresenta os meses que compuseram o TMY2 para Santa Maria a partir do período de anos disponível para sua construção.

Gerou-se a carta bioclimática para os dois arquivos, TRY e TMY2. O desconforto está presente em cerca de $70 \%$ das horas do ano, sendo as principais estratégias a ventilação e inércia térmica para resfriamento (verão) e aquecimento solar passivo e inércia térmica (inverno), como se observa na Tabela 9 e na Figura 5.

Observa-se concentração dos pontos para UR acima dos $30 \%$, com forte concentração à medida que se aproxima de valores mais altos para UR; nota-se também concentração dos pontos em temperaturas inferiores a $28^{\circ} \mathrm{C}$.

O TRY e o TMY2 permitem ainda a análise dos ventos. Na Figura 6 observa-se que a maior velocidade ocorre no inverno, na direção norte, com mais de $4 \mathrm{~m} / \mathrm{s}$, e a menor velocidade ocorre nas fachadas oeste e sudeste, com menos de $2 \mathrm{~m} / \mathrm{s}$. Já no verão as principais orientações para captação de ventos são leste e sudeste, sendo importante prever aberturas nessas fachadas para ventilação natural.

Analisou-se a frequência de ocorrência das TBS por zona (conforto, frio e calor) e da radiação solar global horizontal para manhã, tarde e diária para o TMY2, pois esse arquivo, composto de meses de anos diferentes, tende a ser mais preciso do que o TRY.

As TBS mínimas estão, em sua maioria, fora dos limites de conforto, e as temperaturas máximas estão mais próximas a esses, mas com vários pontos fora dessa zona, considerando Givoni como referência, tal como indicado na Figura 7. A média de temperaturas também mostrou maior desconforto no inverno. Observa-se que a maior porcentagem corresponde à zona de conforto no verão $(72 \%)$, e a maior porcentagem de desconforto por frio ocorre no inverno $(69 \%)$. O desconforto por calor tem menor porcentagem no verão (23\%). Isso indica que o projeto arquitetônico deve privilegiar soluções relativas ao desconforto por frio, segundo a referência adotada (GIVONI, 1992).

É possível perceber na Figura 8 que os meses entre dezembro e março apresentam dados de radiação solar global horizontal maiores (máximo 6.000 $\mathrm{Wh} / \mathrm{m}^{2}$ ), e os meses entre abril e novembro apresentam menor radiação solar, sendo junho o mês com menor valor (abaixo de $2.000 \mathrm{Wh} / \mathrm{m}^{2}$ ). A radiação solar atinge valores mais altos durante a tarde, exceto em novembro e dezembro. Esse resultado indica que a orientação noroeste, no inverno, é mais adequada para captação de radiação para fins de aquecimento passivo.

\section{Dia típico de projeto}

Para Santa Maria, os dias frios abrangem o intervalo de 27 de abril a 22 de outubro, um período de 179 dias. Com exceção de alguns dias com temperatura fora do padrão, nos meses de junho e julho (com temperaturas que satisfizeram o critério adotado), todos os dias quentes puderam ser incluídos em um período de 295 dias, começando em $1^{\circ}$ de agosto e seguindo até 22 de maio do ano subsequente.

Tabela 8 - Meses representativos para formação do TMY2

\begin{tabular}{l|l|l|l|l|l|l|l|l|l|l|l|l}
\hline MẾS & jan & fev & mar & abr & mai & jun & jul & ago & set & out & nov & dez \\
\hline TMY & 2004 & 2005 & 2012 & 2010 & 2009 & 2002 & 2010 & 2006 & 2002 & 2011 & 2005 & 2010 \\
\hline
\end{tabular}

Tabela 9 - Relatório geral das estratégias do TRY para Santa Maria

\begin{tabular}{llcc}
\hline \multirow{2}{*}{ Conforto } & & TRY & TMY2 \\
\cline { 2 - 4 } & & $\mathbf{2 8 , 5 \%}$ & $\mathbf{3 0 , 6 \%}$ \\
\hline \multirow{5}{*}{ Desconforto } & & $\mathbf{7 1 , 5 \%}$ & $\mathbf{6 9 , 4 \%}$ \\
\cline { 2 - 4 } & Calor & $20,3 \%$ & $20,3 \%$ \\
\cline { 2 - 4 } & Ventilação & $18,4 \%$ & $18,4 \%$ \\
\cline { 2 - 4 } & Alta inércia para resfriamento & $0,59 \%$ & $0,74 \%$ \\
\cline { 2 - 4 } & Resfr. evaporativo & $0,56 \%$ & $0,70 \%$ \\
\cline { 2 - 4 } & Ar condicionado & $0,58 \%$ & $0,55 \%$ \\
\cline { 2 - 4 } & Frio & $51,26 \%$ & $49.1 \%$ \\
\cline { 2 - 4 } & Aquecimento solar/Inércia térmica & $29,4 \%$ & $27,1 \%$ \\
\cline { 2 - 4 } & Aquecimento solar passivo & $13 \%$ & $10,5 \%$ \\
\cline { 2 - 4 } & Aquecimento artificial & $8,86 \%$ & $0 \%$ \\
\cline { 2 - 4 } & Umidificação & $0 \%$ & \\
\hline
\end{tabular}

134 Grigoletti, G. de C.; Flores, M. G.; Santos, J. C. P. dos. 
Figura 5 - Cartas bioclimáticas para TRY e TMY2 respectivamente
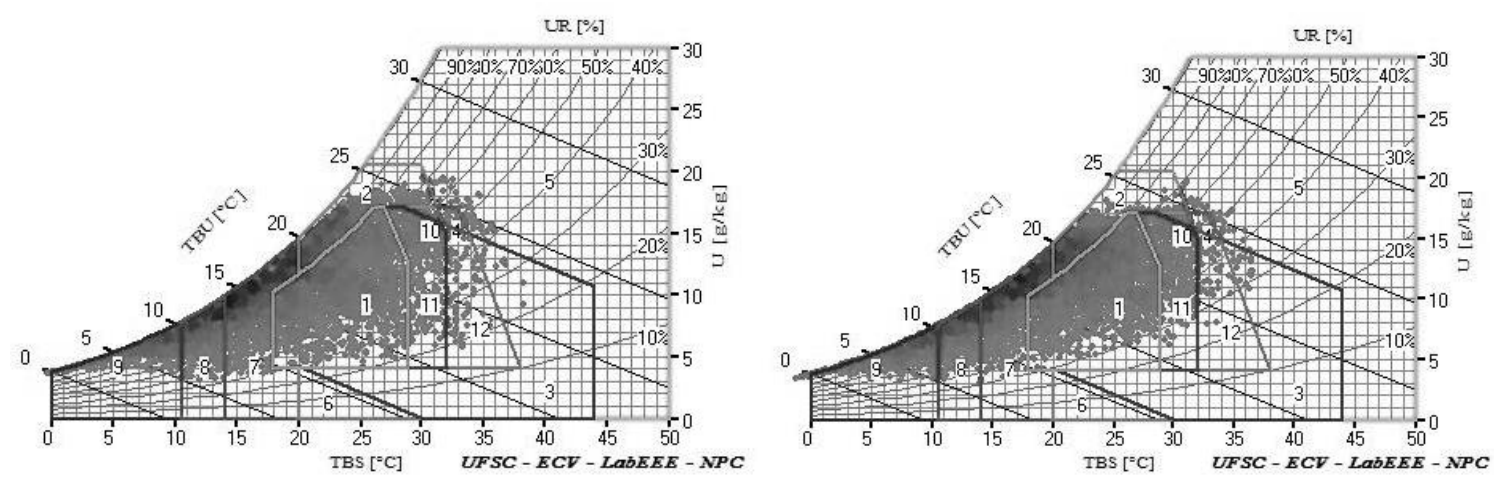

Figura 6 - Velocidades predominantes e frequências por direção e por estações do ano

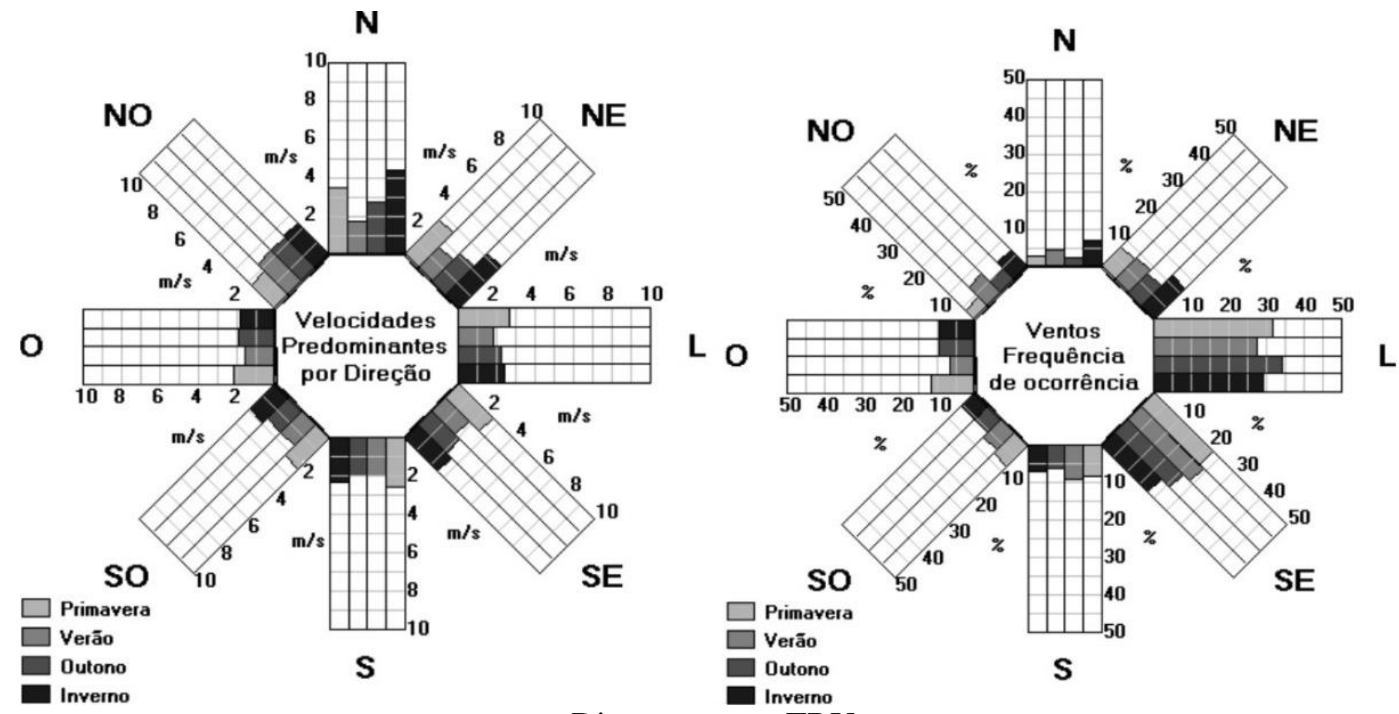

Diagrama para TRY
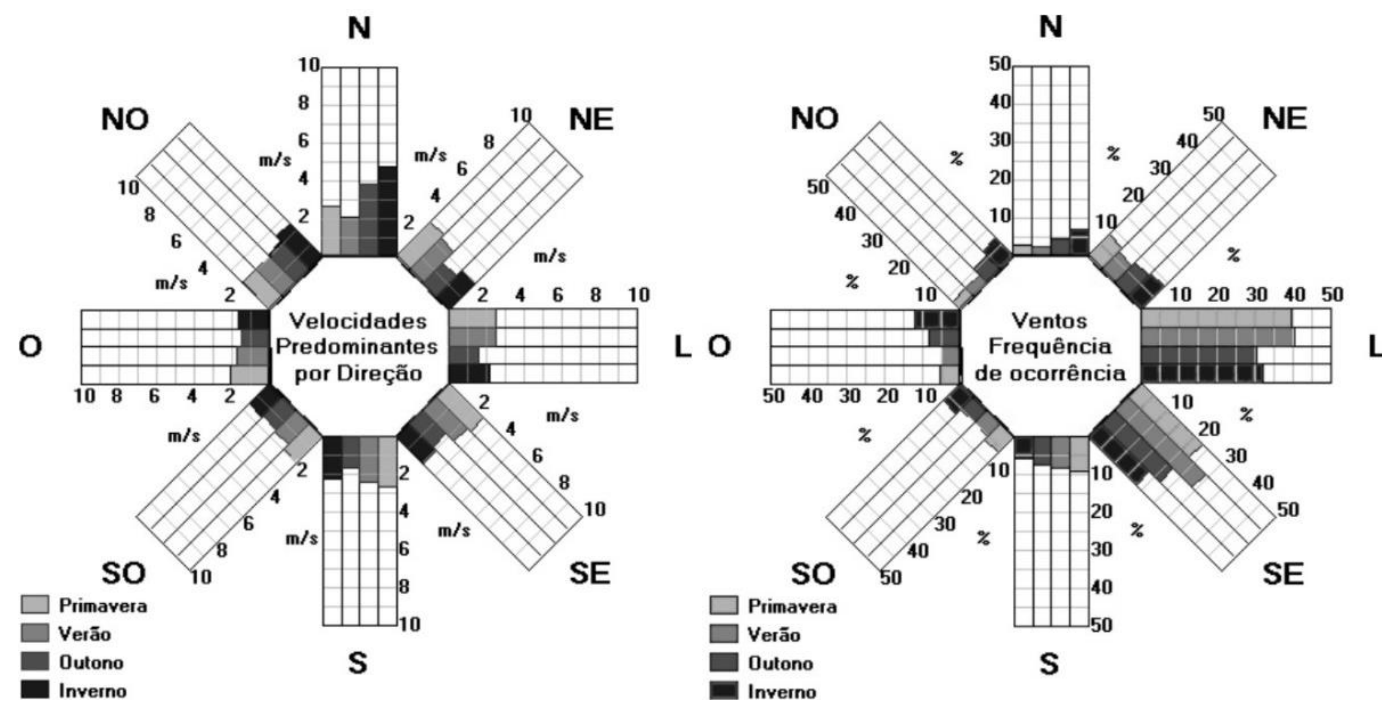

Diagrama para TMY 
Figura 7 - Frequência de ocorrência da temperatura de bulbo seco durante todo o ano

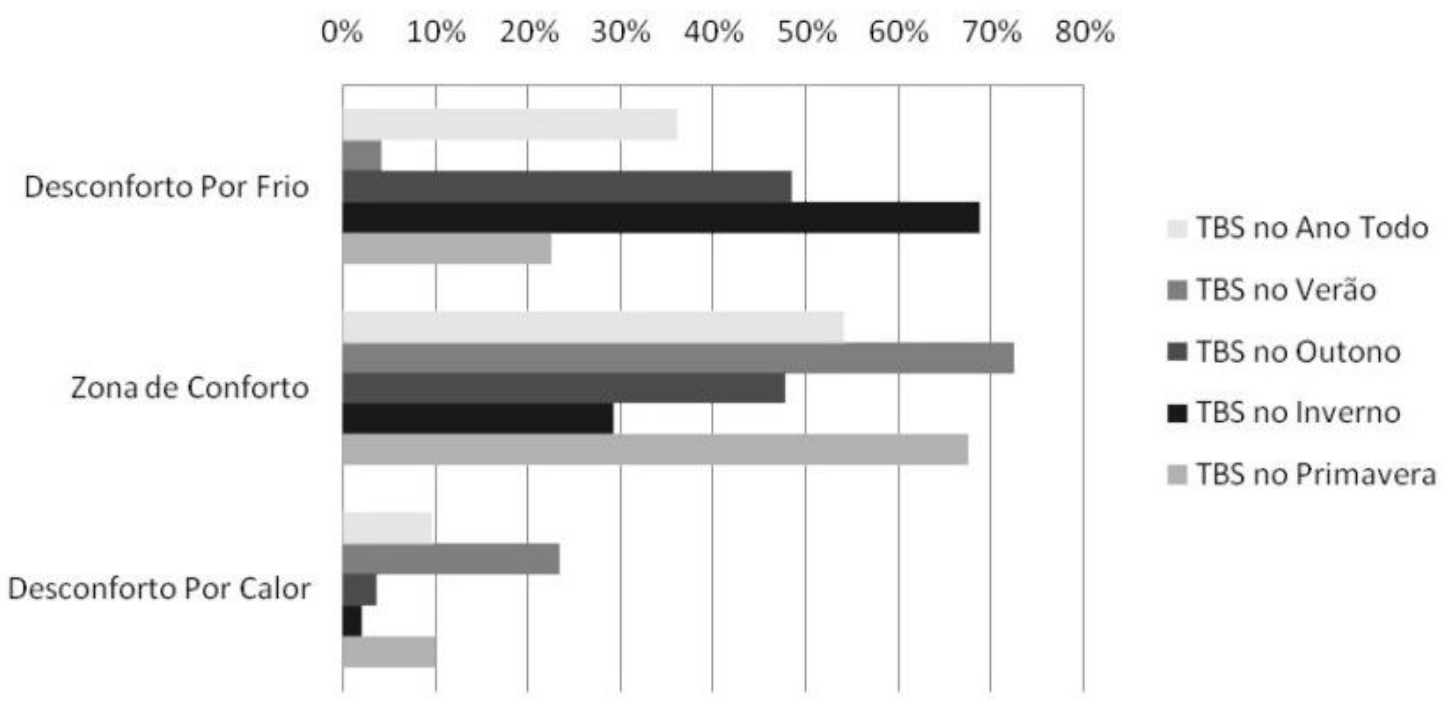

Figura 8 - Médias mensais dos totais diários da radiação global horizontal

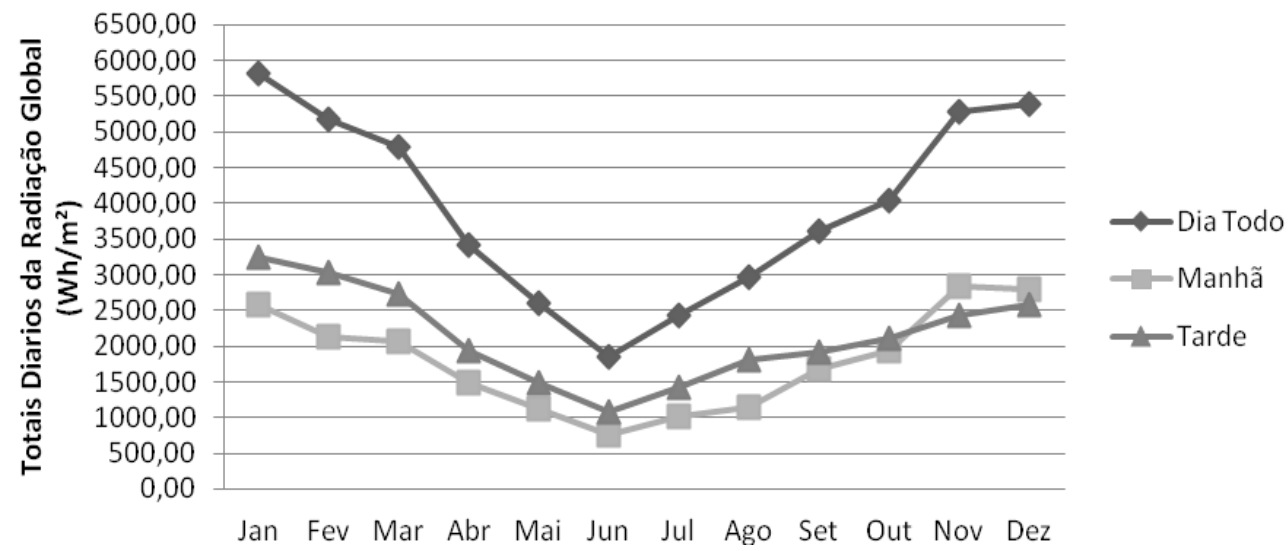

A partir de dados apresentados na Tabela 10 , observa-se que os níveis 5\% e 10\% apresentam valores similares para o inverno. Quanto ao verão, houve maior diferença para a amplitude térmica nos mesmos níveis citados. Os resultados apontam amplitudes de temperatura bastante significativas para a localidade, indicando que a estratégia bioclimática de massa térmica para aquecimento ou resfriamento, como indicado na carta bioclimática, é adequada.

Para inverno, a amplitude da temperatura foi 10,3 ${ }^{\circ} \mathrm{C}\left(-1,8{ }^{\circ} \mathrm{C}\right.$ a $\left.12,2{ }^{\circ} \mathrm{C}\right)$. A velocidade dos ventos oscilou entre $0,0 \mathrm{~m} / \mathrm{s}$ e $2,2 \mathrm{~m} / \mathrm{s}$. Para o dia mais quente do período, a temperatura máxima atingiu $36,7{ }^{\circ} \mathrm{C}$, e a mínima, $30{ }^{\circ} \mathrm{C}$. A velocidade dos ventos oscilou entre $2,0 \mathrm{~m} / \mathrm{s}$ e $7,6 \mathrm{~m} / \mathrm{s}$. Esse resultado demonstra a impossibilidade de aproveitamento da ventilação natural, devido à alta temperatura. Encontrou-se para o período uma amplitude térmica de $38,5^{\circ} \mathrm{C}$, com mínimo de $-1,8$
${ }^{\circ} \mathrm{C}$ e máximo de $36,7^{\circ} \mathrm{C}$. Os dados dessa avaliação foram registrados ao longo do período de 1 ano (2012), o que indica grande amplitude térmica característica.

\section{Comparação dos arquivos TRY- Inmet, TMY e SWERA}

Neste estudo, o TRY encontrado consiste no ano de 2003, coincidindo com o TRY encontrado por Roriz (2012a) ou TRY-Inmet. Logo, a análise comparativa foi feita somente para o arquivo TMY2, gerado neste estudo, com os arquivos SWERA e TRY-Inmet. De acordo com a Figura 9, a distribuição das frequências de ocorrência das TBS é bastante próxima para os três arquivos, com os maiores valores dentro da zona de conforto, e valores mais baixos nos extremos, como esperado.

Quanto aos valores máximos e mínimos registrados para a TBS, no decorrer das $8.760 \mathrm{~h}$, o 
arquivo SWERA apresenta máxima TBS registrada no mês de junho $\left(36,7{ }^{\circ} \mathrm{C}\right)$ e mínima também em junho $\left(-1,2^{\circ} \mathrm{C}\right)$. Já os arquivos TMY2 e TRY apresentam valores de máxima e mínima mais coerentes entre si, $-1,2{ }^{\circ} \mathrm{C}$ (junho) e $-0,3{ }^{\circ} \mathrm{C}$ (julho), 36,6 ${ }^{\circ} \mathrm{C}$ (março) e $38,3{ }^{\circ} \mathrm{C}$ (novembro) respectivamente. $\mathrm{O}$ valor de temperatura máxima para o arquivo SWERA, em junho, pode indicar um comportamento atípico, não se adequando, portanto, à simulação.

Tabela 10 - Dias típicos de projeto com suas temperaturas, UR e amplitudes térmicas

\begin{tabular}{ccccccc}
\hline & \multicolumn{3}{c}{ inverno } & \multicolumn{3}{c}{ verão } \\
\hline variáveis & $2,5 \%$ & $5 \%$ & $10 \%$ & $2,5 \%$ & $5 \%$ & $10 \%$ \\
TBSmin & $2,4{ }^{\circ} \mathrm{C}$ & $6,3{ }^{\circ} \mathrm{C}$ & $6,7{ }^{\circ} \mathrm{C}$ & $23,1{ }^{\circ} \mathrm{C}$ & $22,4{ }^{\circ} \mathrm{C}$ & $21,5{ }^{\circ} \mathrm{C}$ \\
TBSmax & $12,2{ }^{\circ} \mathrm{C}$ & $14,6{ }^{\circ} \mathrm{C}$ & $15,0{ }^{\circ} \mathrm{C}$ & $33,2{ }^{\circ} \mathrm{C}$ & $31,7{ }^{\circ} \mathrm{C}$ & $31,2{ }^{\circ} \mathrm{C}$ \\
URmin & $56 \%$ & $61 \%$ & $61 \%$ & $43 \%$ & $53 \%$ & $50 \%$ \\
URmax & $92 \%$ & $95 \%$ & $94 \%$ & $78 \%$ & $84 \%$ & $88 \%$ \\
amplitude térmica & $9,8{ }^{\circ} \mathrm{C}$ & $8,2{ }^{\circ} \mathrm{C}$ & $8,3{ }^{\circ} \mathrm{C}$ & $10,1{ }^{\circ} \mathrm{C}$ & $9,3{ }^{\circ} \mathrm{C}$ & $10,7{ }^{\circ} \mathrm{C}$ \\
\hline
\end{tabular}

Figura 9 - Frequências de ocorrência de TBS para os arquivos SWERA, TMY2 e TRY-Inmet respectivamente
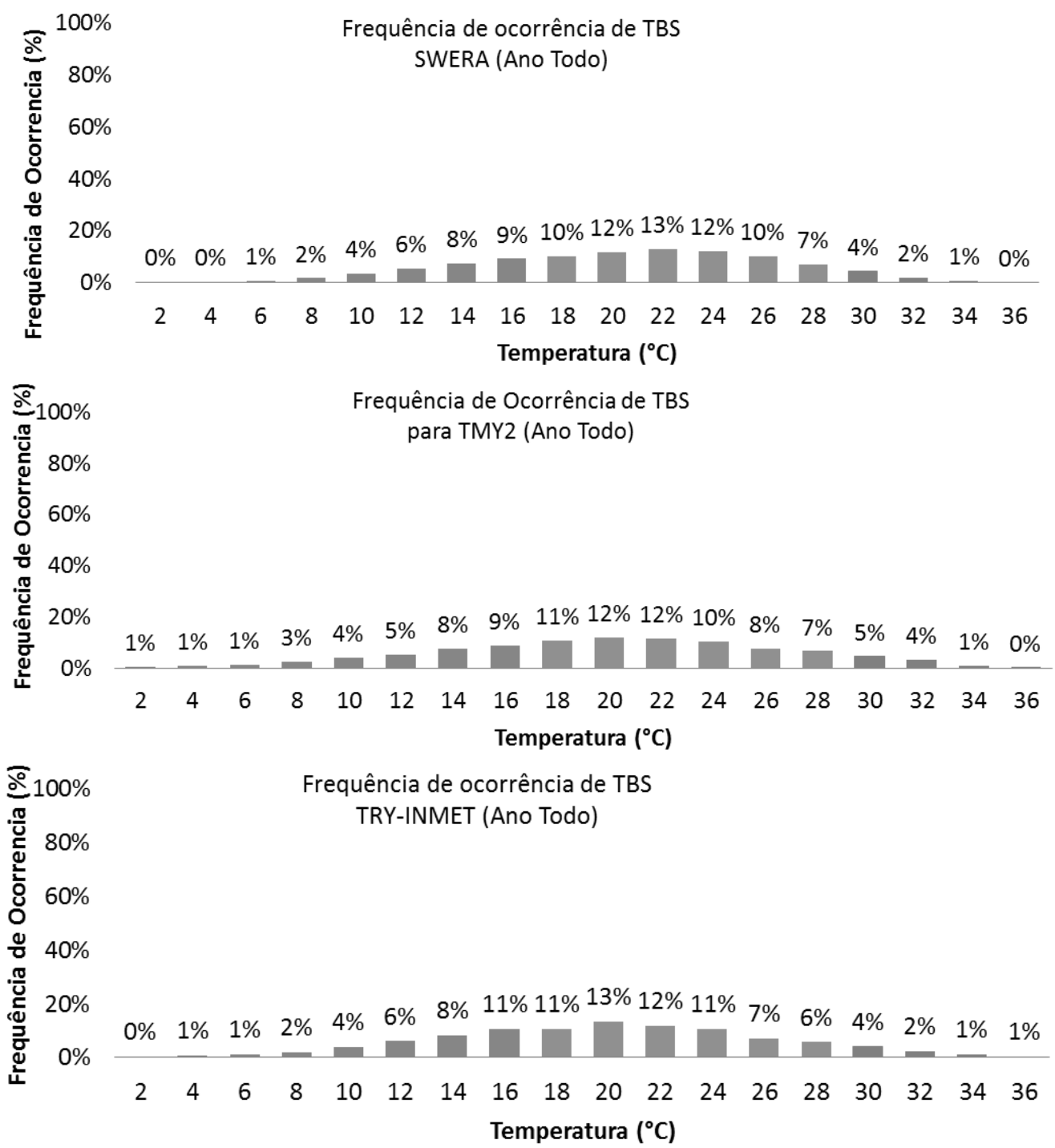
Figura 10 - Frequência de ocorrência de TBS por zona de conforto para os arquivos SWERA, TMY2 e TRY-Inmet (2012) respectivamente

Frequência de ocorrência da TBS para SWERA por Zonas de Conforto

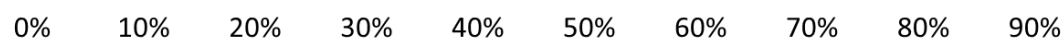

Desconforto Por Frio
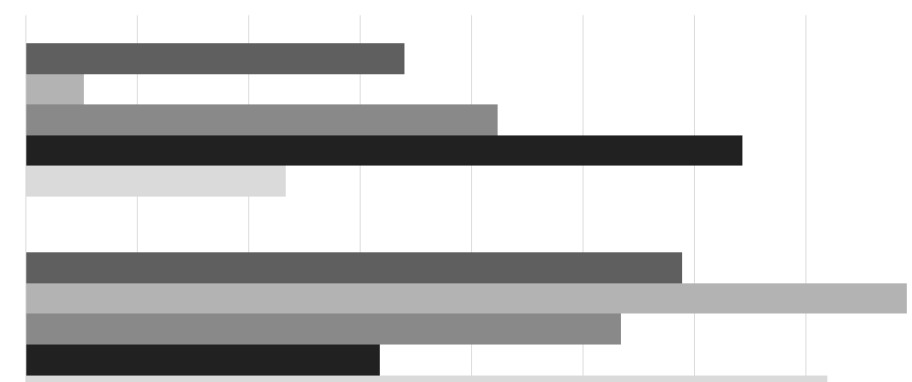

Desconforto Por Calor

Frequência de ocorrência da TBS para TMY2, por Zonas de Conforto

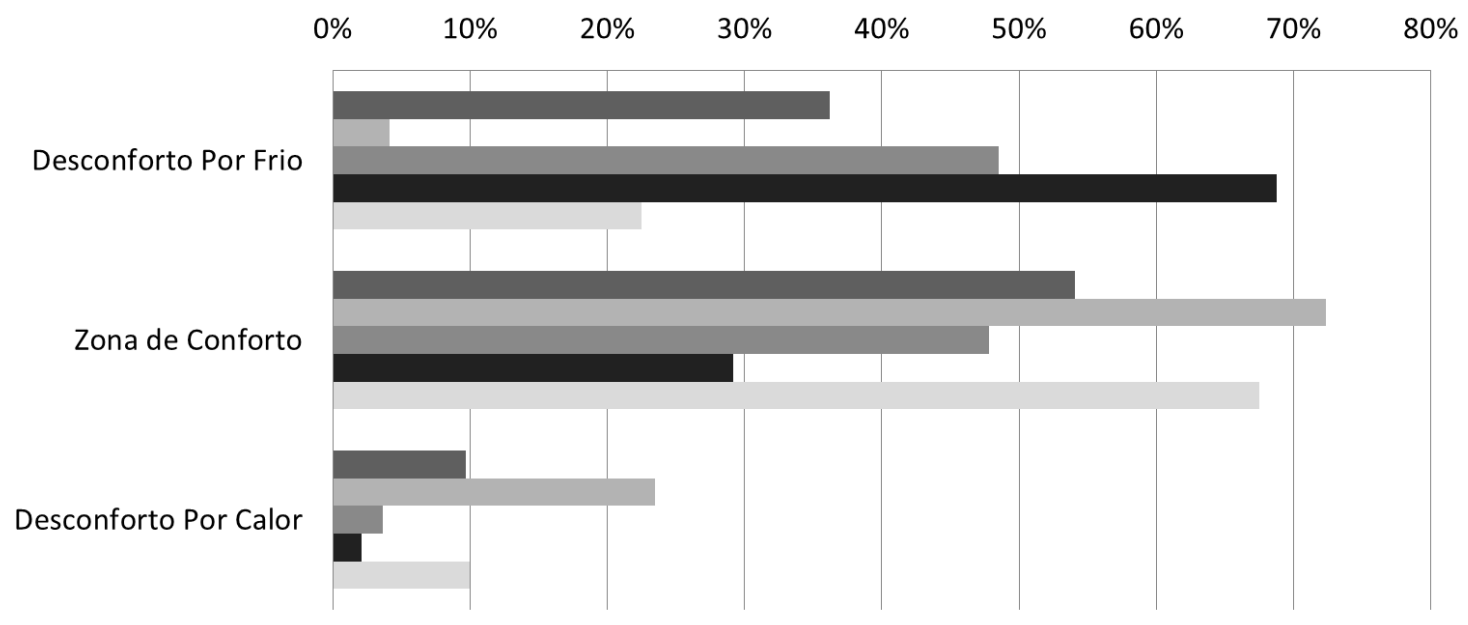

Frequência de ocorrência da TBS para TRY-INMET, por Zonas de Conforto

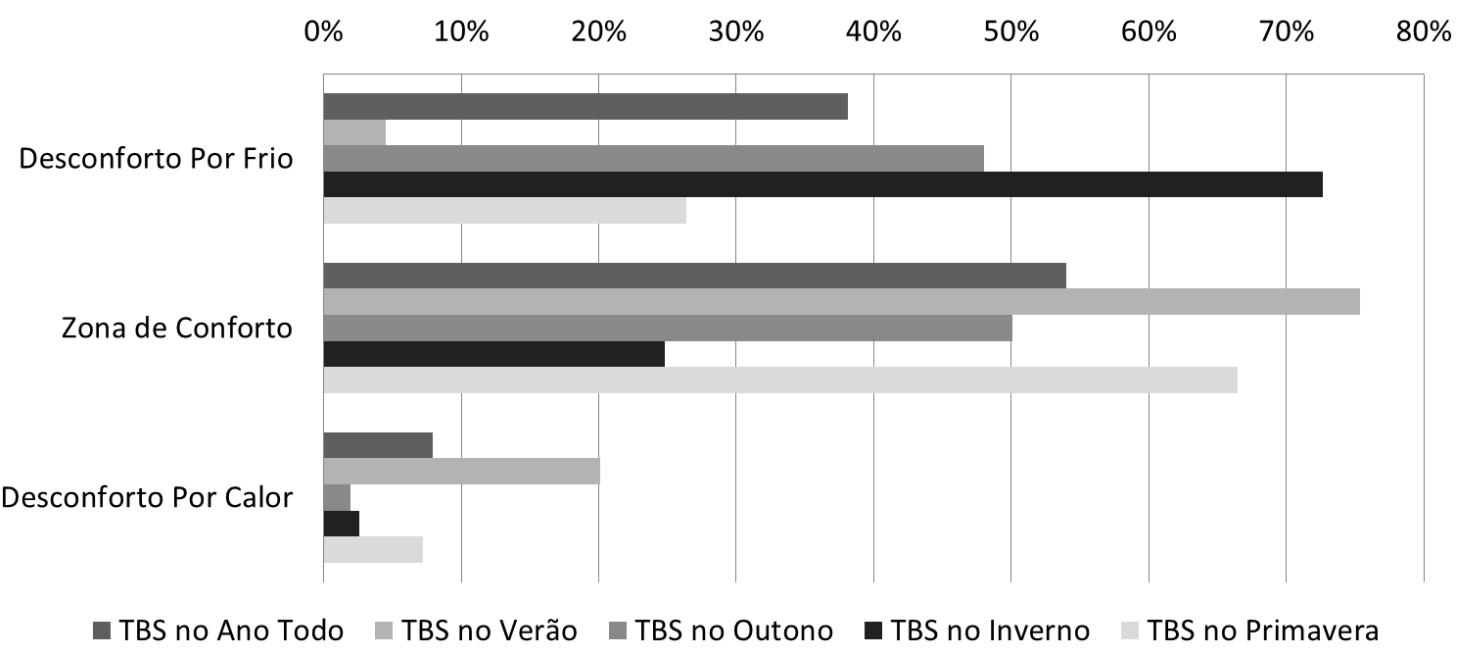

138 Grigoletti, G. de C.; Flores, M. G.; Santos, J. C. P. dos. 
Conforme a Figura 10, o arquivo SWERA apresenta uma percentagem menor de desconforto por frio. Os resultados para os arquivos TMY2 e TRY-Inmet são bastante próximos. No arquivo SWERA a maior porcentagem é na zona de conforto, com maior percentagem no verão, $79 \%$, e a maior porcentagem de desconforto por frio ocorre no inverno, com $64 \%$ de frequência; e desconforto por calor tem menor porcentagem, com $18 \%$ no verão. O arquivo TMY2 apresenta percentagens mais elevadas no verão, em relação ao SWERA, com $23 \%$, e a maior percentagem de desconforto por frio de $69 \%$ no inverno. O arquivo TRY-Inmet (INSTITUTO..., 2014) apresenta percentagem de desconforto por frio, no inverno, de $72 \%$, e desconforto por calor tem menor porcentagem, com a maior atingindo $20 \%$ no verão.

\section{Conclusões}

A partir dos dados do Inmet, com o histórico de 12 anos de dados horários (2002 a 2013) para Santa Maria, contabilizaram-se aproximadamente 850 mil dados, os quais foram tratados para aferir sua coerência, bem como completados os dados faltantes e calculada a temperatura de bulbo úmido e variáveis ligadas à radiação solar não disponíveis de forma direta. Sistematizaram-se os dados na forma de arquivos climáticos para uso em programas de simulação computacional como o Energy Plus, bem como se geraram a carta bioclimática, a rosa dos ventos e o dia típico de projeto.

O tratamento estatístico dos dados e sua conformação em formatos voltados ao projeto de edificações permitiram verificar sua coerência interna, principalmente para as variáveis calculadas, aspectos gerais do clima e melhores estratégias bioclimáticas para a região. Há uma tendência a temperaturas acima das médias registradas.

Considerando a zona de conforto proposta por Givoni (1992), o desconforto por frio é predominante, no entanto a radiação solar global horizontal bem distribuída ao longo do ano (com valores acima da média) permite o uso da estratégia de aquecimento solar passivo e massa térmica para aquecimento para atingir o conforto no inverno. Porém, pelo mesmo motivo, deve ser previsto o sombreamento de aberturas para o verão. O mês de agosto é o mais ventoso, com direção predominante de norte, mas no verão a melhor orientação para captação de ventos é a leste, importante para garantir a estratégia de ventilação natural para desconforto por calor.
Os arquivos TRY e TMY2 ficaram com dados bastante próximos, o que reforça sua coerência. De acordo com o TMY2, as tardes apresentam maior radiação solar que as manhãs, indicando que orientações para captação desse recurso devem ser a norte e noroeste. A maior frequência de temperaturas corresponde ao intervalo de $18{ }^{\circ} \mathrm{C}$ a $22{ }^{\circ} \mathrm{C}$. Os dias típicos de projeto referentes aos níveis $5 \%$ e $10 \%$ foram muito parecidos para o período de anos analisado. A amplitude térmica entre $8{ }^{\circ} \mathrm{C}$ e $10{ }^{\circ} \mathrm{C}$ indica a possibilidade de uso da massa térmica tanto para aquecimento quanto para resfriamento.

O TRY gerado neste estudo, ano de 2003, coincidiu com o mesmo ano achado por Roriz (2012a), mantendo-se como referência. Esse resultado pode demonstrar a estabilidade do comportamento climático dos intervalos de anos estudados. A comparação dos arquivos TRYInmet, TMY2 e SWERA demonstra comportamentos muito semelhantes tanto para temperatura de bulbo seco, umidade relativa do ar e radiação global horizontal. Nota-se o valor de TBS máxima para o SWERA no mês de junho, o que pode comprometer simulações feitas com base neste arquivo, pois representa um comportamento atípico para o mês.

Os resultados obtidos com as diferentes sistematizações, em geral, indicaram as mesmas estratégias bioclimáticas, ou seja, aquecimento solar passivo e massa térmica no inverno, e ventilação natural no verão.

Com o tratamento dos dados climáticos para a cidade de Santa Maria apresentado nesta pesquisa, foi possível complementar uma base de informações fundamentais para o projeto bioclimático, mesmo para um período de 12 anos, contribuindo para propostas arquitetônicas adequadas ao clima local e de melhor eficiência energética. A sistematização de dados apresentada, embora para Santa Maria, pode ser aplicada a outros contextos com dados horários disponíveis, de forma a contribuir para o projeto bioclimático e para a melhor eficiência energética de edificações situadas em outras localidades.

\section{Referências}

AKUTSU, M.; PEDROSO, N. G. Dia Típico de Projeto Para Desenvolvimento de Projeto Arquitetônico. Construção São Paulo, v. 2079, 1987.

AMERICAN SOCIETY OF HEATING REFRIGERATING AND AIR-CONDITIONING ENGINEERS. ASHRAE Fundamentals

Handbook. Atlanta: ASHRAE, 2001. 
AYOADE, J. O. Introdução à Climatologia Para os Trópicos. 4. ed. Rio de Janeiro: Bertrand Brasil, 1996.

CARLO, J; LAMBERTS, R. Processamento de Arquivos Climáticos Para Simulação do Desempenho Energético de Edificações. In: ARQUIVOS Climáticos. Florianópolis: UFSC/LabEEE. 2005. Disponível em: $<$ http://www.labeee.ufsc.br/downloads/arquivosclimaticos>. Acesso em: 20 jan. 2012

DUFFIE, J. A.; BECKMANN, W. A. Solar Engineering of Thermal Processes. New York: John Wiley \& Sons, Inc., 1980.

FERREIRA, F. C. Procedimento de Avaliação de Conforto Ambiental e Eficiência Energética Aplicado a Um Caso Típico da Rede Estadual de Escolas Públicas de Minas Gerais. Belo Horizonte, 2006. 256 f. Dissertação (Mestrado em Arquitetura) - Escola de Arquitetura, Universidade Federal de Minas Gerais, Belo Horizonte, 2006.

GIVONI, B. Comfort, Climate Analysis and Building Design Guidelines. Energy and Buildings, v.18, n. 1, p. 11-23, 1992.

GOUlart, S. V. G. Dados Climáticos Para Avaliação De Desempenho Térmico De Edificações. Florianópolis, 1993. 124 f. Dissertação (Mestrado em Engenharia Civil) Universidade Federal de Santa Catarina, Florianópolis, 1993.

GOULART, S. V. G.; LAMBERTS, R.; FIRMINO, S. Dados Climáticos Para Projeto e Avaliação Energética de Edificações Para 14 Cidades Brasileiras. 2. ed. Florianópolis: Núcleo de Pesquisa em Construção/UFSC, 1998.

GOULART, S.; LAMBERTS, R. Dados Climáticos Para Avaliação de Desempenho Térmico de Edificações. In: ENCONTRO NACIONAL DE CONFORTO NO AMBIENTE CONSTRUÍDO, 2., Florianópolis, 1993. Anais... Florianópolis: ENCAC, 1993.

GUIMARÃES, I.; CARLO, J. Desenvolvimento do Arquivo Climático de Viçosa Para Simulação Computacional de Desempenho TermoEnergético. In: SIMPÓSIO DE PESQUISA E EXTENSÃO EM ARQUITETURA E URBANISMO, 1., Viçosa, 2010. Anais... Viçosa, 2010.

INSTITUTO NACIONAL DE

METEOROLOGIA. [Página Eletrônica]. Disponível em: <http://www.inmet.gov.br>. Acesso em: 25 jun. 2014.
KINSEL, L. S. Avaliação do Conforto e da Energia em Edifícios Residenciais de Porto Alegre. Porto Alegre, 2009. 194 f. Dissertação (Mestrado em Arquitetura) - Escola de Arquitetura, Universidade Federal do Rio Grande do Sul, Porto Alegre, 2009.

\section{LABORATÓRIO DE EFICIÊNCIA} ENERGÉTICA EM EDIFICAÇÕES. Arquivos Climáticos. Florianópolis. Universidade Federal de Santa Catarina. Disponível em: <http://www.labeee.ufsc.br/downloads/arquivosclimaticos>. Acesso em: 23 jun. 2014.

LAMBERTS, R.; DUTRA, L; PEREIRA, F. O. R. Eficiência Energética na Arquitetura. São Paulo: PW, 2014.

LOUREIRO, K. C. G. Análise de Desempenho Térmico e Consumo de Energia de Residências da Cidade de Manaus. Florianópolis, 2003. 160 f. Dissertação (Mestrado em Engenharia Civil) Escola de Engenharia, Universidade Federal de Santa Catarina, Florianópolis, 2003.

MARTINAZZO, C. A. Modelos de Estimativas de Radiação Solar Para Elaboração de Mapas Solarimétricos. Porto Alegre, 2004. 210 f. Dissertação (Mestrado em Engenharia Mecânica) Escola de Engenharia, Universidade Federal do Rio Grande do Sul, Porto Alegre, 2004.

MENDONÇA, F.; DANNI-OLIVEIRA, I. M. Climatologia: noções básicas e climas do Brasil. São Paulo: Oficina de Textos, 2007.

PEREIRA, I. Novas Metodologias Para Simulação Energética de Edificações: estudo de Caso. Belo Horizonte, 2004. 174 f. Dissertação (Mestrado em Engenharia Civil) - Escola de Engenharia, Universidade Federal de Minas Gerais, Belo Horizonte, 2004.

PITTA, T. O. O Estudo de Métodos Diretos e Indiretos de Estimativa de Irradiação Solar Global Diária Horizontal a partir de Observações Superficiais de Cobertura Total de Nuvens em Florianópolis, SC. Florianópolis, 2001. 113 f. Dissertação (Mestrado em Engenharia Civil) - Escola de Engenharia, Universidade Federal de Santa Catarina, Florianópolis, 2001.

PITTIGLIANI, M. Controle de Qualidade De Dados Hidrometeorológicos Do Simepar. In: CONGRESSO BRASILEIRO DE METEOROLOGIAM, 11., Rio de Janeiro, 2000. Anais... Rio de Janeiro: SBMET, 2000. 
POUEY, J. A. Projeto de Edificação Residencial Unifamiliar para a Zona Bioclimática 2 com Avaliação Termo Energética por Simulação Computacional. Pelotas, 2011. 137 f. Dissertação (Mestrado em Arquitetura e Urbanismo) - Escola de Arquitetura, Universidade Federal de Pelotas, Pelotas, 2011.

RORIZ, M. Arquivos Climáticos de Municípios Brasileiros. Florianópolis: UFSC/LabEEE, 2012a.

RORIZ, M. Segunda Proposta de Revisão do Zoneamento Bioclimático Brasileiro.

Florianópolis: UFSC/LabEEE. 2012b.

SATTLER, M. Dias Típicos Para o Projeto Térmico de Edificações em Porto Alegre. Porto Alegre: CIENTEC, 1989.
SCHELLER, C. et al. Análise de Arquivos Climáticos Para a Simulação de Desempenho Energético de Edificações. Florianópolis: UFSC/Centro Brasileiro de Eficiência Energética em Edificações, 2015.

UNIVERSIDADE FEDERAL DO PARANÁ. Curso Técnico de Petróleo. Estatística Descritiva. Curitiba. Disponível em: <http://www.tecnicodepetroleo.ufpr.br/ apoio_didatico.htm>. Acesso em: 18 nov. 2012.

\section{Agradecimentos}

Ao $\mathrm{CNPq}$, por recursos que financiaram esta pesquisa, e ao Latecae, pelo apoio à fundamentação do método.

Giane de Campos Grigoletti

Departamento de Arquitetura e Urbanismo, Centro de Tecnologia | Universidade Federal de Santa Maria | Av. Roraima, n. 1000, Prédio 30, Sala 204, Camobi | Santa Maria - RS - Brasil | CEP 97105-900 | Tel.: (55) 3220-8771 | E-mail: grigoletti@smail.ufsm.br

\section{Michelle Gomes Flores}

Programa de Pós-Graduação em Engenharia Civil | Universidade Federal de Santa Maria, Tel.: (55) 3220-8837 |

E-mail: mickgflores@yahoo.com.br

Joaquim Cesar Pizzutti dos Santos

Departamento de Estruturas e Construção Civil, Centro de Tecnologia | Universidade Federal de Santa Maria | Tel.: (55) 3220-8144 | E-mail: joaquimpizzutti@hotmail.com

\section{Revista Ambiente Construído}

Associação Nacional de Tecnologia do Ambiente Construído

Av. Osvaldo Aranha, $99-3^{\circ}$ andar, Centro

Porto Alegre - RS - Brasil CEP 90035-190

Telefone: +55 (51) 3308-4084

Fax: +55 (51) 3308-4054

www.seer.ufrgs.br/ambienteconstruido

E-mail: ambienteconstruido@ufrgs.br 